Research Article

\title{
Theoretical and Experimental Study on the Transient Time-Frequency Characteristics of the Bending-Torsional Coupling Motions of a Rub-Impact Dual-Rotor System
}

\author{
Tian Gao, ${ }^{1,2}$ Shuqian Cao ${ }^{1},{ }^{1,2}$ and Tiancheng Zhang ${ }^{1,2}$ \\ ${ }^{1}$ Department of Mechanics, Tianjin University, Tianjin 300354, China \\ ${ }^{2}$ Tianjin Key Laboratory of Nonlinear Dynamics and Control, Tianjin 300354, China
}

Correspondence should be addressed to Shuqian Cao; sqcao@tju.edu.cn

Received 16 July 2020; Revised 11 November 2020; Accepted 20 December 2020; Published 7 January 2021

Academic Editor: Selda Oterkus

Copyright (c) 2021 Tian Gao et al. This is an open access article distributed under the Creative Commons Attribution License, which permits unrestricted use, distribution, and reproduction in any medium, provided the original work is properly cited.

\begin{abstract}
This paper focuses on the fault characteristics of the bending and torsional motions of a rub-impact dual-rotor system caused by aircraft flight maneuvers. The equations of the bending-torsional coupling motion of a dual-rotor system are established considering a low-pressure rotor rub-impact fault and the transient barrel roll flight of an aircraft. The 4th Runge-Kutta method with varied steps is used to obtain the bending and torsional responses. Then, the influences of the system parameters, including the rub-impact stiffness, friction coefficient, and rotating speed, on the bending and torsional motions of the dual-rotor system are investigated in detail. At last, a rotor rubbing experiment is carried out, verifying the validity of the simulation results. The results show that the rub-impact stiffness affects bending vibration significantly and the torsional motion is sensitive to the friction coefficient. Correspondingly, the torsional responses show apparent fractional fault frequencies and rotating fault frequencies within the whole region of the rub-impact stiffness. The bending responses can only display fault frequencies at certain rub-impact stiffness. As for the rotating speed, the torsional responses are also more effective than the bending responses for the rub-impact fault detection at the low- and high-speed regions. The results will contribute to a comprehensive basis for the rub-impact fault detection.
\end{abstract}

\section{Introduction}

The rub-impact of rotor-to-stator, which is one of the most common faults in aeroengine rotor systems, could lead to catastrophic failure sometimes, such as blade fracture and engine flameout $[1,2]$. Therefore, the early fault detection of rub-impact is crucial for avoiding the disasters. Many researchers have made a profound study on the periodic motions $[3,4]$, chaotic-responses $[5,6]$, and harmonic frequency characteristics [7-9] of the bending responses of the rub-impact rotor system. However, under the condition of the rub-impact, the torsional responses also displayed abundant fault dynamic responses because of the friction torque caused by the rub-impact of the rotor-to-stator [10]. Thus, it is important to investigate the fault characteristics of the bending and torsional motions of the rub-impact rotor system, so as to provide a comprehensive theoretical basis for the state detection and fault diagnosis.

The mass imbalance of the rotor system is one of the major factors leading to the bending-torsional coupling motions. The analyses of the bending-torsional coupling responses, caused by the mass imbalance, were mainly aimed at the slender flexible rotor, such as turbogenerator unit.. $\mathrm{He}$ et al. [11] built the differential equations of the bendingtorsional coupling vibration for a Jeffcott rotor model with unbalance mass. They found that the combined resonance of the coupled bending-torsional motion happened when the rotating frequency of the rotor system was equal to the sum (or the difference) of the natural frequencies of the bending and torsional vibration. Li and Chen [12] studied the subsynchronous resonance and combined resonance of the bending and torsional motions of a low-pressure cylinder- 
generator rotor system through the singularity theory for the two-state variable system. The transition sets and bifurcation diagrams were obtained which could be used for rotor system optimization. Recently, much attention has been paid to the bending-torsional coupling motions of the fault rotor systems. The effect of the parallel misalignment and angular misalignment on the bending and torsional responses of two rotating shafts was examined through the theoretical and numerical analyses $[13,14]$. It was concluded that the parallel misalignment could lead to the bending-torsional coupling motions and the angular misalignment increased the volume of the instability region. Darpe et al. $[15,16]$ investigated the coupling between the transversal, torsional, and longitudinal vibration of a transverse cracked rotor, in which the excitation in one mode resulted in an interaction between all the modes. Patel and Darpe [17] studied the coupled bending-torsional vibrations of a rotor system with rub and crack. The rub excitations and breathing influences of the crack affected the rotor response in both bending and torsional modes. Lin and Chu [18] carried out the dynamic analysis of a rotor system with a slant crack on the shaft. They found that there were coupling stiffness of the bendingtorsion, bending-tension, and torsion-tension for a slantcracked shaft. Wang and Jiang [19] derived the motion equations of a dual-rotor system considering unbalancemisalignment coupling faults. The complicated vibration responses affected by rotational speed, mass eccentricity, misalignment angle, and parallel misalignment were investigated.

Regarding the bending-torsional motions of the rubimpact rotor system, Lu and Chu [20] found they consisted of the similar frequency components under the conditions of no rub, full annual rub, and partial rub. Yang et al. [21] studied the bending-torsional coupled vibration of an aeroengine model subjected to blade-casing rub in presence of nonuniform initial gap. The results showed that the nonuniform initial gap led to rich vibration phenomena in the dynamic responses, especially in the torsional responses. Zhang and Ding $[22,23]$ investigated the influence of rubimpact on the bending and torsional vibrations of a two-disk rotor-stator system. The results indicated that the spectrum analyses of the torsional vibrations were more suitable to determine the axial contact-rubs. Xu et al. [24] studied the vibration frequency spectrum characteristics of a rub-impact dual-rotor system based on a finite element model. Zhang et al. [25] analyzed the coupled bending and torsional motions of a rub-impact dual-rotor system through numerical simulation and experiment. The bending and torsional vibrations both contained multiple frequency, fractional frequency, and combined frequency of the rotating frequency and multiple/fractional frequency.

The maneuver load during flight maneuvers of an aircraft could lead to a rub-impact phenomenon of the aeroengine rotor system, accompanied with complex nonlinear behavior [4, 26-28]. However, the rub-impact fault characteristics of the bending vibration do not behave evidently under some certain system parameters. In this study, the equations of the bending-torsional coupling motion of a rub-impact dual-rotor system with maneuver load are established by using Lagrange equation firstly. The transition of the rotor system from nonrubbing to rub-impact, caused by the transient maneuvering flight, is obtained through the numerical integration method. Then, the time-frequency features of the bending and torsional vibrations of the rubimpact dual-rotor system are investigated during the flight of an aircraft. A variety of comparisons for the rub-impact fault features of the bending and torsional motions are observed under varied rub-impact stiffness, friction coefficients, and rotating speeds. At last, a rotor rubbing experiment, under maneuvering flight, is carried out, verifying the validity of the simulation results. The research of this study provides a deeper and more comprehensive theoretical basis for the state detection and fault diagnosis of the aeroengine rotor system during flight maneuvers.

\section{Mathematical Modeling}

2.1. Geometrical Model of Dual-Rotor System. AL-31F is one of the most common aero-engines. Based on the basic structure of the $\mathrm{AL}-31 \mathrm{~F}$, the aeroengine rotor system is simplified as a dual-rotor model, which consists of a lowpressure rotor and a high-pressure rotor, as shown in Figure 1. The low-pressure rotor adopts the three-point supporting structures in which the mounting positions are at the $1^{\#}, 2^{\#}$, and $5^{\#}$. The high-pressure rotor absorbs the twopoint supporting schemes in which the mounting positions are at the $3^{\#}$ and $4^{\#}$. The low-pressure rotor and the highpressure rotor are coupled through the intermediate ball bearing at $4^{\#}$. The components of the low-pressure rotor system include the lumped mass of the disks $m_{2}$ and $m_{5}$ and the lumped mass of the shaft $m_{1}, m_{3}, m_{4}$, and $m_{6}$. The highpressure rotor is regarded as a rigid rotor which only consists of the lumped mass $m_{7}$. All the supporting structures, except the intermediate ball bearing $4^{\#}$, are considered as elastic supporting systems with elastic supports and rolling bearings in series. They are simplified to spring-damping systems, wherein the stiffness and damping of the elastic supports are defined as $k_{1}, k_{2}, k_{3}, k_{5}, c_{1}, c_{2}, c_{3}$, and $c_{5}$, respectively. All the disks of the dual-rotor system have an unbalance magnitude and the eccentricity of the disks are described by $e_{i}(i=2,5$, and 7$)$ separately. In addition, the rub-impact fault occurs at the disk 2.

2.2. Equation of Motion of Dual-Rotor System with Rub-Impact Fault in Maneuvering Flight. Lagrange's equation is used to derive the equations of motion of the dual-rotor system. It is defined as [29]

$$
\frac{d}{\mathrm{~d} t}\left(\frac{\partial L}{\partial \dot{q}_{j}}\right)-\frac{\partial L}{\partial q_{j}}+\frac{\partial D}{\partial \dot{q}_{j}}=Q_{j}, \quad(j=1,2, \ldots, k),
$$

where $L=T-V, T$ and $V$ are the kinetic energy and potential energy functions of the dual-rotor system, $D$ is the dissipative energy function, $q_{j}$ is the generalized coordinate in the $j$ th degree of freedom, and $Q_{j}$ is the generalized force corresponding to $q_{j}$. The process of the derivation is as follows. First, the kinetic energy, potential energy and dissipative energy of the dual-rotor system are obtained. Then, the 


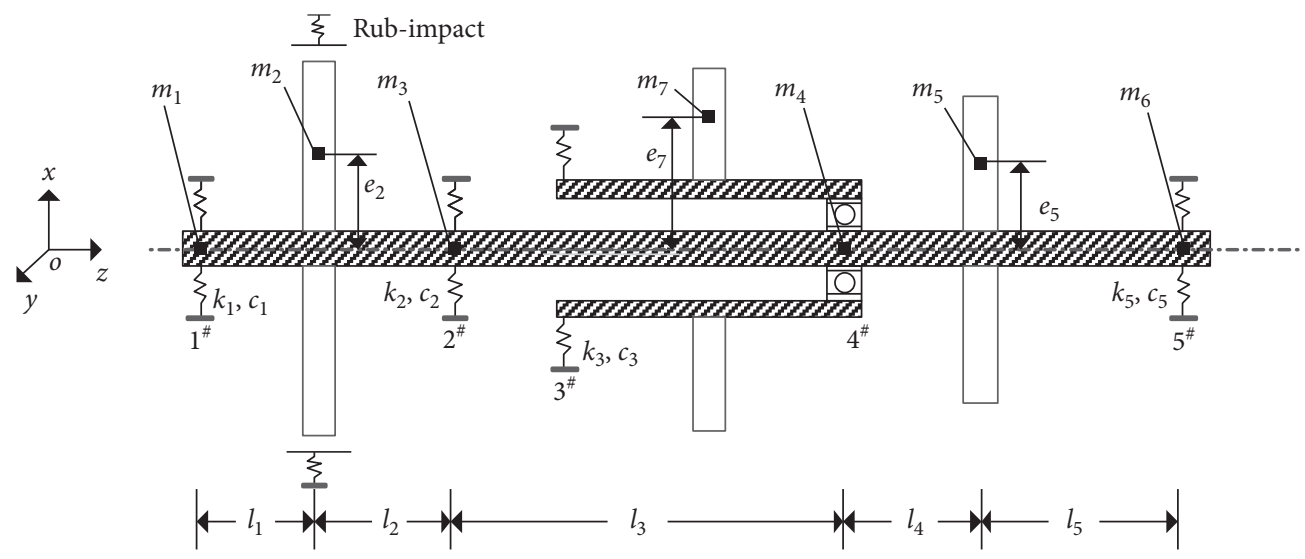

Figure 1: Schematic diagram of the dual-rotor system.

generalized forces of the ball bearing, rub-impact fault, gravity, and maneuver load are given. At last, the equations of the bending-torsional coupling motion are calculated by inserting the kinetic energy, potential energy, dissipative energy, and generalized forces into Lagrange's equation given in equation (1).

2.2.1. Energy Functions of Dual-Rotor System. Based on the modeling method of Reference [25], the following assumption is made for the dual-rotor system. As we know, the low-pressure rotor is a relatively flexible slender shaft. The high-pressure rotor is short and the shaft diameter of which is large. Because the short and thick shaft is harder to display large torsional angle, the torsional vibrations of the highpressure rotor are neglected. The bending and torsional motions are only considered at the disk $m_{i}(i=2,5)$ of the low-pressure rotor. They are described by the generalized coordinates $\left(x_{i}, y_{i}, \alpha_{i}\right)(i=2,5)$, where $x_{i}$ and $y_{i}$ are the centroid displacements of the disk and $\alpha_{i}$ is the torsional angle. Meanwhile, the torsional angle satisfies the following function $\varphi_{i}=\omega_{\text {low }} t+\alpha_{i}+\phi_{i}(i=2,5)$, where $\varphi_{i}$ is the phase angle of the mass centroid of the disk, $\omega_{\text {low }}$ is the rotating speed of the low-pressure rotor, and $\phi_{i}$ is the initial phase angle. Regarding the high-pressure rotor $m_{i}(i=7)$ and the lump mass of the shaft of the low-pressure rotor $m_{i}(i=1,3$, $4,6)$, the bending motions are taken into account simply. They are defined as $\left(x_{i}, y_{i}\right)(i=1,3,4,6,7)$, where $x_{i}$ and $y_{i}$ are the centroid displacements of the high-pressure rotor and the shaft of the low-pressure rotor, respectively. In addition, the rotating speed of the high-pressure rotor is described by $\omega_{\text {high }}$, which satisfies $\omega_{\text {high }}=\gamma_{\omega} \omega_{\text {low }}\left(\gamma_{\omega}\right.$ is the rotating speed ratio of the high-pressure rotor to low-pressure rotor). Therefore, there are 16 degrees of freedom of the dual-rotor system which consist of 14 bending motions and 2 torsional motions. They are given by the generalized vector $\mathbf{q}$ :

$$
\mathbf{q}=\left[x_{1}, x_{2}, \ldots, x_{7}, y_{1}, y_{2}, \ldots, y_{7}, \alpha_{2}, \alpha_{5}\right]^{\mathrm{T}},
$$

where the bending generalized vector $\mathrm{x}, \mathrm{y}$ and the torsional generalized vector $\alpha$ are separately expressed as

$$
\begin{gathered}
\mathbf{x}=\left[\begin{array}{l}
x_{1} \\
x_{2} \\
x_{3} \\
x_{4} \\
x_{5} \\
x_{6} \\
x_{7}
\end{array}\right], \\
\mathbf{y}=\left[\begin{array}{l}
y_{1} \\
y_{2} \\
y_{3} \\
y_{4} \\
y_{5} \\
y_{6} \\
y_{7}
\end{array}\right], \\
\boldsymbol{a}=\left[\begin{array}{l}
\alpha_{2} \\
\alpha_{5}
\end{array}\right] .
\end{gathered}
$$

Because there are eccentricities $e_{i}(i=2,5,7)$ of the rotating disks, the mass centroid of the high-pressure rotor and the low-pressure rotor is described by the generalized vectors $x_{c}$ and $y_{c}$ : 


$$
\mathbf{x}_{c}=\left[\begin{array}{c}
x_{1} \\
x_{2}+e_{2} \cos \varphi_{2} \\
x_{3} \\
x_{4} \\
x_{5}+e_{5} \cos \varphi_{5} \\
x_{6} \\
x_{7}+e_{7} \cos \varphi_{7}
\end{array}\right],
$$

The kinetic energy $T$ of the dual-rotor system consists of translational kinetic energy $T_{\mathrm{t}}$ and rotational kinetic energy $T_{\mathrm{r}}$. It is defined as

$$
\begin{aligned}
T & =T_{\mathrm{t}}+T_{\mathrm{r}} \\
& =\frac{1}{2} \dot{x}_{c}^{T} \mathbf{M}_{c} \dot{x}_{c}^{T}+\frac{1}{2} \dot{y}_{c}^{T} \mathbf{M}_{c} \dot{y}_{c}^{T}+\frac{1}{2} \dot{\boldsymbol{\varphi}} \mathbf{J}_{c} \dot{\boldsymbol{\varphi}},
\end{aligned}
$$

where

$$
\dot{x}_{\mathrm{c}}=\left[\begin{array}{c}
\dot{x}_{1} \\
\dot{x}_{2}-e_{2} \dot{\varphi}_{2} \sin \varphi_{2} \\
\dot{x}_{3} \\
\dot{x}_{4} \\
\dot{x}_{5}-e_{5} \dot{\varphi}_{5} \sin \varphi_{5} \\
\dot{x}_{6} \\
\dot{x}_{7}-e_{7} \dot{\varphi}_{7} \sin \varphi_{7}
\end{array}\right] \text {, }
$$

$$
\dot{y}_{\mathrm{c}}=\left[\begin{array}{c}
\dot{y}_{1} \\
\dot{y}_{2}+e_{2} \dot{\varphi}_{2} \cos \varphi_{2} \\
\dot{y}_{3} \\
\dot{y}_{4} \\
\dot{y}_{5}+e_{5} \dot{\varphi}_{5} \cos \varphi_{5} \\
\dot{y}_{6} \\
\dot{y}_{7}+e_{7} \dot{\varphi}_{7} \cos \varphi_{7}
\end{array}\right] \text {, }
$$$$
\dot{\boldsymbol{\varphi}}=\left[\begin{array}{c}
\omega_{\mathrm{low}}+\dot{\alpha}_{2} \\
\omega_{\mathrm{low}}+\dot{\alpha}_{5} \\
\omega_{\mathrm{high}}
\end{array}\right]
$$$$
\mathbf{M}_{c}=\left[\begin{array}{cccc}
m_{1} & 0 & 0 & 0 \\
0 & m_{2} & 0 & 0 \\
0 & 0 & \ddots & 0 \\
0 & 0 & 0 & m_{7}
\end{array}\right],
$$

$$
\mathbf{J}_{\mathrm{c}}=\left[\begin{array}{ccc}
J_{2}+m_{2} e_{2}^{2} & 0 & 0 \\
0 & J_{5}+m_{5} e_{5}^{2} & 0 \\
0 & 0 & J_{7}+m_{7} e_{7}^{2}
\end{array}\right] \text {. }
$$

where $\dot{x}_{\mathrm{c}}$ and $\dot{y}_{\mathrm{c}}$ are the translational velocity vectors of the mass centroid, $\dot{\varphi}$ is the rotating velocity vector of the disks, $\mathbf{M}_{\mathrm{c}}$ is the mass matrix, and $\mathbf{J}_{\mathrm{c}}$ is the moment of inertia relative to the mass centroid of the disks. Moreover, $J_{i}=1 / 2 m_{i} R_{i}^{2}$ ( $i=2,5,7)$, where $R_{i}$ are the radii of the disks.

The potential energy $U_{\mathrm{e}}$ of the dual-rotor system consists of the elastic potential energy of the shaft and the elastic potential energy of the elastic supports. It is defined as

$$
U_{\mathrm{e}}=\frac{1}{2} \mathbf{x}^{\mathrm{T}} \mathbf{K}_{x} \mathbf{x}+\frac{1}{2} \mathbf{y}^{\mathrm{T}} \mathbf{K}_{y} \mathbf{y}+\frac{1}{2} \boldsymbol{\alpha}^{\mathrm{T}} \mathbf{K}_{\mathrm{t}} \boldsymbol{\alpha},
$$

where

$$
\begin{aligned}
& \mathbf{K}_{x}=\mathbf{K}_{y}=\left[\begin{array}{ccccccc}
k_{1}+k_{6} & -k_{6} & 0 & 0 & 0 & 0 & 0 \\
-k_{6} & k_{6}+k_{7} & -k_{7} & 0 & 0 & 0 & 0 \\
0 & -k_{7} & k_{2}+k_{7}+k_{8} & -k_{8} & 0 & 0 & 0 \\
0 & 0 & -k_{8} & k_{8}+k_{9} & -k_{9} & 0 & 0 \\
0 & 0 & 0 & -k_{9} & k_{9}+k_{10} & -k_{10} & 0 \\
0 & 0 & 0 & 0 & -k_{10} & k_{5}+k_{10} & 0 \\
0 & 0 & 0 & 0 & 0 & 0 & k_{3}
\end{array}\right] \text {, } \\
& \mathbf{K}_{\mathrm{t}}=\left[\begin{array}{cc}
k_{t 1}+k_{t 2} & -k_{t 2} \\
-k_{t 2} & k_{t 2}
\end{array}\right] \text {, }
\end{aligned}
$$


where $\mathbf{K}_{x}$ and $\mathbf{K}_{y}$ are the bending stiffness matrices of the $x$ - and $y$-directions, respectively, and $\mathbf{K}_{\mathrm{t}}$ is the torsional stiffness matrix. In addition, the bending stiffness and torsional stiffness of the shaft are given by

$$
\begin{aligned}
& k_{6}=\frac{3 E I}{l_{1}^{3}}, \\
& k_{7}=\frac{12 E I}{l_{2}^{3}}, \\
& k_{8}=\frac{12 E I}{l_{3}^{3}}, \\
& k_{9}=\frac{12 E I}{l_{4}^{3}}, \\
& k_{10}=\frac{3 E I}{l_{5}^{3}}, \\
& k_{t 1}=\frac{G I_{\mathrm{P}}}{l_{1}}, \\
& k_{t 2}=\frac{G I_{\mathrm{P}}}{l_{2}+l_{3}+l_{4}},
\end{aligned}
$$

where

where $k_{1}, k_{2}, k_{3}$, and $k_{5}$ are the stiffness of the elastic supports, the values of which are obtained from the elastic stiffness of a squirrel cage, $k_{6}, k_{7}, k_{8}, k_{9}$, and $k_{10}$ are the bending stiffness corresponding to the shaft segment $l_{1}, l_{2}, l_{3}$, $l_{4}$, and $l_{5}$, respectively, $k_{\mathrm{t} 1}$ and $k_{\mathrm{t} 2}$ are the torsional stiffness corresponding to the shaft segment $l_{1}$ and $l_{2}+l_{3}+l_{4}$, separately, $E$ and $G$ are Young's modulus and the shear modulus of the shaft, and $I$ and $I_{\mathrm{P}}$ are the moment of inertia and the polar moment of inertia of the shaft.

The dissipative energy of the dual-rotor system can be described by the Rayleigh energy dissipation function:

$$
D=\frac{1}{2} \dot{x}^{T} \mathbf{C}_{x} \dot{x}+\frac{1}{2} \dot{y}^{\mathrm{T}} \mathbf{C}_{y} \dot{y}+\frac{1}{2} \dot{\alpha}^{\mathrm{T}} \mathbf{C}_{t} \dot{\alpha},
$$

where

$$
\begin{aligned}
& \mathbf{C}_{x}=\mathbf{C}_{y}=\left[\begin{array}{ccccccc}
c_{1}+c_{6} & -c_{6} & 0 & 0 & 0 & 0 & 0 \\
-c_{6} & c_{6}+c_{7} & -c_{7} & 0 & 0 & 0 & 0 \\
0 & -c_{7} & c_{2}+c_{7}+c_{8} & -c_{8} & 0 & 0 & 0 \\
0 & 0 & -c_{8} & c_{8}+c_{9} & -c_{9} & 0 & 0 \\
0 & 0 & 0 & -c_{9} & c_{9}+c_{10} & -c_{10} & 0 \\
0 & 0 & 0 & 0 & -c_{10} & c_{5}+c_{10} & 0 \\
0 & 0 & 0 & 0 & 0 & 0 & c_{3}
\end{array}\right], \\
& \mathbf{C}_{\mathrm{t}}=\left[\begin{array}{cc}
c_{t 1}+c_{t 2} & -c_{t 2} \\
-c_{t 2} & c_{t 2}
\end{array}\right],
\end{aligned}
$$

where $\mathbf{C}_{x}, \mathbf{C}_{y}$, and $\mathbf{C}_{\mathrm{t}}$ are the damping matrices corresponding to the bending and torsional motions, respectively. $c_{1}, c_{2}, c_{3}$, and $c_{5}$ are the given damping coefficients of the elastic supports, $c_{6}, c_{7}, c_{8}, c_{9}$, and $c_{10}$ are the given damping coefficients corresponding to the bending motion of the shaft segments $l_{1}, l_{2}, l_{3}, l_{4}$, and $l_{5}$, separately, and $c_{\mathrm{t} 1}$ and $c_{\mathrm{t} 2}$ are the damping coefficients corresponding to the torsional motions of the shaft segment $l_{1}$ and $l_{2}+l_{3}+l_{4}$, respectively. In this study, the damping coefficients $c_{i}(i=1,2, \ldots, 10)$ are directly given, based on the Rayleigh damping ratio of the rotor system valuing around 0.1 . Then, the initial free vibration of the simulation model can be reduced quickly.
2.2.2. Generalized Force of Intermediate Ball Bearing. The model of the intermediate ball bearing is shown in Figure 2 . The inner race of the ball bearing is directly fixed on the low-pressure rotor and the outer race is directly joined together with the high-pressure rotor. We assume that the balls are arranged equidistantly at the cage of the bearing. Then, the rotating speed of the cage of the bearing can be defined as

$$
\omega_{\mathrm{c}}=\frac{\omega_{\text {low }} R_{\text {inner }}+\omega_{\text {high }} R_{\text {outer }}}{R_{\text {inner }}+R_{\text {outer }}},
$$




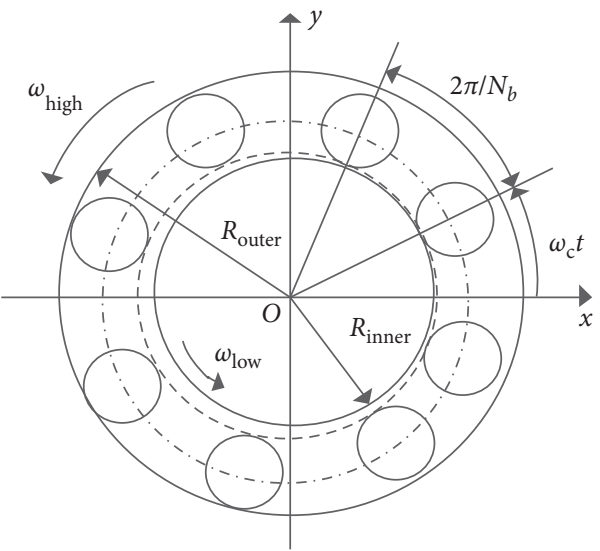

FIgURE 2: Intermediate ball bearing model.

where $R_{\text {inner }}$ and $R_{\text {outer }}$ are the radii of the inner race and outer race of the ball bearing, respectively, and $\omega_{\text {low }}$ and $\omega_{\text {high }}$ are the rotating speeds of the low-pressure rotor and highpressure rotor, separately.

The number of the balls is described by $N_{\mathrm{b}}$. Then the location of the $j$ th ball is given by

$$
\theta_{j}=\omega_{c} t+\left(\frac{2 \pi(j-1)}{N_{b}}\right), \quad\left(j=1,2, \ldots, N_{b}\right)
$$

The relative displacement between the inner and outer races of the ball bearing is expressed by $\left(x_{7}-x_{4}, y_{7}-y_{4}\right)$. The initial bearing clearance is defined as $\delta_{0}$. Then, the contact deformation of the $j$ th ball is expressed as

$$
\delta_{j}=\left(x_{7}-x_{4}\right) \cos \theta_{j}+\left(y_{7}-y_{4}\right) \sin \theta_{j}-\delta_{0} .
$$

According to the Hertzian contact theory [30], the force of the intermediate ball bearing is given by

$$
\left[\begin{array}{c}
F_{\mathrm{b} x} \\
F_{\mathrm{b} y}
\end{array}\right]=C_{b} \sum_{j=1}^{N_{b}}\left(\delta_{j}\right)^{(3 / 2)} H\left(\delta_{j}\right)\left[\begin{array}{c}
\cos \theta_{j} \\
\sin \theta_{j}
\end{array}\right],
$$

where $C_{b}$ is the Hertz contact stiffness and $H()$ is the Heaviside function.

2.2.3. Force of Rub-Impact Fault. The schematic diagram of the rub-impact fault is shown in Figure 3. The relative displacement between the disk and the stator is described by $r_{2}=\left(x_{2}^{2}+y_{2}^{2}\right)^{(1 / 2)}$. The initial clearance between the disk and the stator is defined as $\delta$.

When the rub-impact fault happens, there are normal force $F_{\mathrm{n}}$ and tangential force $F_{\tau}$ applied to the rotor system. According to [31], the rub-impact force can be expressed by

$$
\left[\begin{array}{c}
F_{\mathrm{r} x} \\
F_{\mathrm{r} y}
\end{array}\right]=-\frac{k_{\mathrm{r}}\left(r_{2}-\delta\right)}{r_{2}}\left[\begin{array}{cc}
1 & -\mu \\
\mu & 1
\end{array}\right]\left[\begin{array}{l}
x_{2} \\
y_{2}
\end{array}\right], \quad\left(r_{2}>\delta\right),
$$

where $k_{\mathrm{r}}$ and $\mu$ are the contact stiffness and the friction coefficient between the disk and stator, respectively. In addition, the friction applied to the disk leads to friction torque which is given by

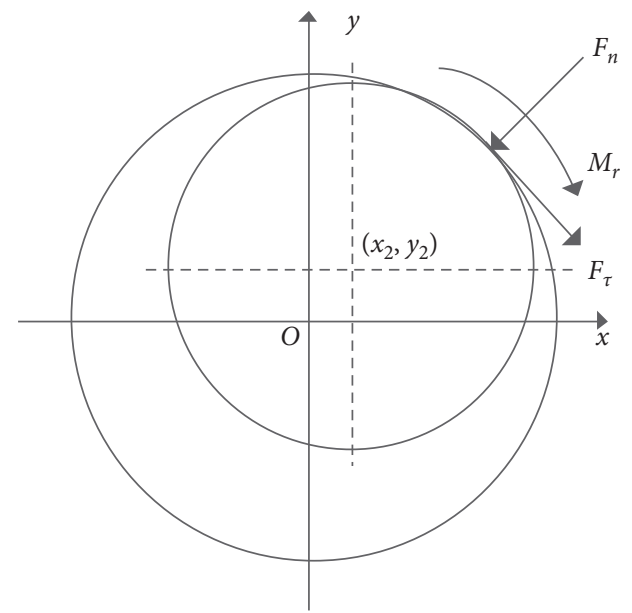

FIgURE 3: Rub-impact fault model.

$$
M_{\mathrm{r}}=\mu k_{\mathrm{r}} R_{2}\left(r_{2}-\delta\right), \quad\left(r_{2}>\delta\right)
$$

where $R_{2}$ is the radius of the disk. Moreover, from equation (17), we get that that the friction torque is the function consisting of the bending displacement $r_{2}$. Meanwhile, we know that the friction torque is the main factor resulting in the torsional motion. Therefore, the friction torque is one of the major factors leading to the bending-torsional coupling motion.

2.2.4. Maneuver Load and Gravity. As shown in Figure 4, the influence of the barrel roll flight of an aircraft on the rubimpact dual-rotor system is investigated. The process of the transient barrel roll flight is simplified as three stages: at first $(t \in[0 \mathrm{~s}, 2 \mathrm{~s}))$, the aircraft keeps the steady-state flight, and it enters into the barrel roll flight at $t=2 \mathrm{~s}$ and quits the barrel roll flight at $t=4 \mathrm{~s}$. Then, it returns to the steady flight again $(t \in(4 \mathrm{~s}, 6 \mathrm{~s}])$

The actual barrel roll flight is very complicated. We have to make some simplified assumptions to study its influence. As shown in Figure 5, the barrel roll flight is considered as a circular motion. The rolling speed and rolling radius of the aircraft are defined as $\omega_{\mathrm{b} z}$ and $R_{\mathrm{b} z}$, respectively. In addition, because the rotation of the aircraft is faster than the revolution during the barrel roll flight, the rotation speed of the aircraft is defined as $2 \omega_{\mathrm{bz}}$. To express the load state of the rotor system conveniently, two Cartesian coordinated references are used. The inertial reference frame $O-X Y$, fixed to the ground is used for describing the flight status of the aircraft. The generalized reference frame $o-x y$, fixed to the aircraft, is used to describe the vibration of the dual-rotor system. The dual-rotor system is subjected to gravity $m_{i} g$ and additional inertial force $m_{i} \omega_{\mathrm{bz}}^{2} R_{\mathrm{bz}}$ due to the barrel roll flight of the aircraft. The gravity is always vertically downward. The additional inertial force is directed to the center of the rolling circle. Because the rolling direction of the aircraft is the same as the rotating direction of the dualrotor system, there is no additional inertia moment applied to rotor system. Then, the generalized forces of the maneuver 


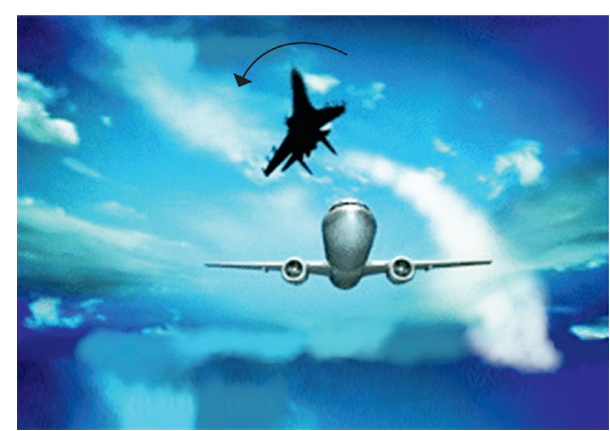

FIgURE 4: Barrel roll flight of an aircraft.

load and gravity are obtained by decomposing them into the generalized reference frame $o-x y$ :

$$
\left[\begin{array}{c}
F_{\mathrm{gxi}} \\
F_{\mathrm{gyi}}
\end{array}\right]=\left[\begin{array}{c}
m_{i} \omega_{\mathrm{bz}}^{2} R_{\mathrm{bz}} \cos \theta_{\mathrm{bz}}-m_{i} g \sin 2 \theta_{\mathrm{bz}} \\
-m_{i} \omega_{\mathrm{bz}}^{2} R_{\mathrm{bz}} \sin \theta_{\mathrm{bz}}-m_{i} g \cos 2 \theta_{\mathrm{bz}}
\end{array}\right],
$$

where $\dot{\theta}_{\mathrm{bz}}=\omega_{\mathrm{bz}}(t \in[2 \mathrm{~s}, 4 \mathrm{~s}])$.

2.2.5. Equation of Bending-Torsional Coupling Motion of Dual-Rotor System. The equations of the bending-torsional coupling motion of the rub-impact dual-rotor system can be calculated by substituting the energy functions and generalized forces into equation (1):

$$
\mathbf{M} \ddot{q}+\mathbf{C} \dot{q}+\mathbf{K q}=\mathbf{F}_{\mathrm{r}}+\mathbf{F}_{\mathrm{b}}+\mathbf{F}_{\mathrm{u}}+\mathbf{F}_{\mathrm{g}},
$$

where

$$
\begin{aligned}
& \mathbf{M}=\left[\begin{array}{ccc}
\mathbf{M}_{\mathrm{c}} & 0 & 0 \\
0 & \mathbf{M}_{\mathrm{c}} & 0 \\
0 & 0 & \mathbf{J}_{\mathrm{c}}^{\prime}
\end{array}\right], \\
& \mathbf{C}=\left[\begin{array}{ccc}
\mathbf{C}_{x} & 0 & 0 \\
0 & \mathbf{C}_{y} & 0 \\
0 & 0 & \mathbf{C}_{\mathrm{t}}
\end{array}\right] \text {, } \\
& \mathbf{K}=\left[\begin{array}{ccc}
\mathbf{K}_{x} & 0 & 0 \\
0 & \mathbf{K}_{y} & 0 \\
0 & 0 & \mathbf{K}_{\mathrm{t}}
\end{array}\right] \text {, } \\
& \mathbf{J}_{\mathrm{c}}^{\prime}=\left[\begin{array}{cc}
J_{2}+m_{2} e_{2}^{2} & 0 \\
0 & J_{5}+m_{5} e_{5}^{2}
\end{array}\right] \text {, } \\
& \mathbf{F}_{\mathrm{r}}=\left[\begin{array}{llllllllllllllll}
0 & F_{\mathrm{r} x} & 0 & 0 & 0 & 0 & 0 & 0 & F_{\mathrm{r} y} & 0 & 0 & 0 & 0 & 0 & M_{\mathrm{r}} & 0
\end{array}\right]^{\mathrm{T}} \text {, } \\
& \mathbf{F}_{\mathrm{b}}=\left[\begin{array}{llllllllllllllll}
0 & 0 & 0 & F_{\mathrm{b} x} & 0 & 0 & -F_{\mathrm{b} x} & 0 & 0 & 0 & F_{\mathrm{b} y} & 0 & 0 & -F_{\mathrm{b} y} & 0 & 0
\end{array}\right]^{\mathrm{T}} \text {, } \\
& \mathbf{F}_{\mathrm{u}}=\left[\begin{array}{llllllllllllllll}
0 & F_{\mathrm{u} x 2} & 0 & 0 & F_{\mathrm{u} x 5} & 0 & \mathrm{~F}_{\mathrm{u} x 7} & 0 & F_{\mathrm{u} y 2} & 0 & 0 & F_{\mathrm{u} y 5} & 0 & F_{\mathrm{uy} 7} & F_{\mathrm{u} \alpha 1} & F_{\mathrm{u} \alpha 2}
\end{array}\right]^{\mathrm{T}} \text {, } \\
& \mathbf{F}_{\mathrm{g}}=\left[\begin{array}{llllllllllllllll}
F_{\mathrm{g} x 1} & F_{\mathrm{g} x 2} & F_{\mathrm{g} x 3} & F_{\mathrm{g} x 4} & F_{\mathrm{g} x 5} & F_{\mathrm{g} x 6} & F_{\mathrm{g} x 7} & F_{\mathrm{gy} 1} & F_{\mathrm{gy} 2} & F_{\mathrm{gy} 3} & F_{\mathrm{gy} 4} & F_{\mathrm{gy} 5} & F_{\mathrm{gy} 6} & F_{\mathrm{gy} 7} & 0 & 0
\end{array}\right]^{\mathrm{T}}, \\
& F_{\mathrm{u} x 2}=m_{2} e_{2}\left(\dot{\varphi}_{2}^{2} \cos \varphi_{2}+\ddot{\varphi}_{2} \sin \varphi_{2}\right), F_{\mathrm{u} x 5}=m_{5} e_{5}\left(\dot{\varphi}_{5}^{2} \cos \varphi_{5}+\ddot{\varphi}_{5} \sin \varphi_{5}\right), F_{\mathrm{u} x 7}=m_{7} e_{7} \omega_{\mathrm{h}}^{2} \cos \left(\omega_{h} t\right), \\
& F_{\mathrm{u} y 2}=m_{2} e_{2}\left(\dot{\varphi}_{2}^{2} \sin \varphi_{2}-\ddot{\varphi}_{2} \cos \varphi_{2}\right), F_{\mathrm{u} y 5}=m_{5} e_{5}\left(\dot{\varphi}_{5}^{2} \sin \varphi_{5}-\ddot{\varphi}_{5} \cos \varphi_{5}\right), F_{\mathrm{u} y 7}=m_{7} e_{7} \omega_{\mathrm{h}}^{2} \sin \left(\omega_{h} t\right) \text {, } \\
& F_{\mathrm{u} \alpha 1}=m_{2} e_{2}\left(\ddot{x}_{2} \sin \varphi_{2}-\ddot{y}_{2} \cos \varphi_{2}\right), F_{\mathrm{u} \alpha 2}=m_{5} e_{5}\left(\ddot{x}_{5} \sin \varphi_{5}-\ddot{y}_{5} \cos \varphi_{5}\right) \text {, }
\end{aligned}
$$

where $\mathbf{M}, \mathbf{C}$, and $\mathbf{K}$ are the generalized mass matrix, damping matrix, and stiffness matrix, respectively, $\mathbf{F}_{\mathrm{r}}$ and $\mathbf{F}_{\mathrm{b}}$ are the generalized force of the rub-impact fault and intermediate ball bearing, separately, $\mathbf{F}_{\mathrm{u}}$ is the unbalanced force, and $\mathbf{F}_{\mathrm{g}}$ is the generalized resultant force of the maneuver load and gravity, $\varphi_{i}(i=2,5)$ are the time-varying phase angles of the mass centroid of the disks, which have been defined in the Section 2.2.1. In addition, from the derivation of the $\mathbf{F}_{\mathrm{u}}$, we know that unbalanced force is another factor leading to the bending-torsional coupling motion.
2.3. Simulation Parameter and Calculation Process. Because of the strong nonlinearity of the rotor system, the numerical integration method is adopted to solve the (19). The bending-torsional coupling dynamic responses of the rub-impact dual-rotor are calculated via the 4th RungeKutta method with varied step. According to Reference [25], the simulation parameters of the dual-rotor system are listed in Table 1.

In the process of the dynamic analysis, the relative torsional angle $\Delta \alpha=\alpha_{2}-\alpha_{5}$ is chosen to show the torsional 


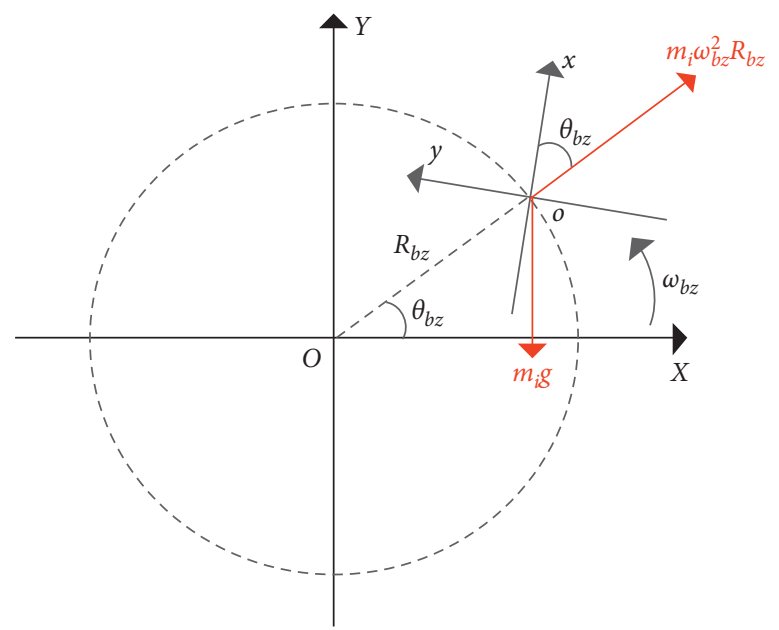

FIGURE 5: Force analysis of the rotor system during the barrel roll flight of an aircraft.

TABle 1: Parameters of dual-rotor model.

\begin{tabular}{lcc}
\hline Physical description & Parameter & Value \\
\hline Mass & $m_{1}, m_{2}, m_{3}, m_{4}, m_{5}, m_{6}, m_{7}(\mathrm{~kg})$ & $2,10,2,2,6,2,8$ \\
Radius of the disk & $R_{2}, R_{5}(\mathrm{~m})$ & $0.075,0.03$ \\
Initial phase angle of the disk & $\phi_{2}, \phi_{5}(\mathrm{rad})$ & 0,0 \\
Eccentricity of the disk & $e_{2}, e_{5}, e_{7}(\mu \mathrm{m})$ & $46.35,46.35,47.5$ \\
Stiffness of the elastic support & $k_{1}, k_{2}, k_{3}, k_{5}(\mathrm{~N} / \mathrm{m})$ & $10^{6,}, 10^{6,}, 10^{6,} 10^{6}$ \\
Length of the shaft segment & $l_{1}, l_{2}, l_{3}, l_{4}, l_{5}(\mathrm{~m})$ & $0.33,0.33,0.6,0.23,0.23$ \\
Material properties of the shaft & $E, G(\mathrm{~Pa})$ & $2 \times 10^{11}, 7.7 \times 10^{10}$ \\
Physical properties of the shaft & $I, I_{\mathrm{p}}\left(\mathrm{m}^{4}\right)$ & $1.178 \times 10^{-7}, 2.356 \times 10^{-7}$ \\
Damping of the elastic support & $c_{1}, c_{2}, c_{3}, c_{5}(\mathrm{~N} \cdot \mathrm{s} / \mathrm{m})$ & $300,300,300,300$ \\
Damping of the bending motion & $c_{6}, c_{7}, c_{8}, c_{9}, c_{10}(\mathrm{~N} \mathrm{~s} / \mathrm{m})$ & $150,150,150,150,150$ \\
Damping of the torsional motion & $c_{\mathrm{tl}}, c_{\mathrm{t} 2}(\mathrm{~N} \cdot \mathrm{m} / \mathrm{s} / \mathrm{rad})$ & 1,1 \\
Parameters of the rub-impact fault & $k_{\mathrm{r}}(\mathrm{N} / \mathrm{m}), \delta(\mathrm{m}), \mu$ & $8 \times 10^{6}, 1.34 \times 10^{-4}, 0.1$ \\
Parameters of the ball bearing & $C_{\mathrm{b}}\left(\mathrm{N} / \mathrm{m}^{3 / 2}\right), \delta_{0}, R_{\mathrm{inner}}, R_{\mathrm{outer}}(\mathrm{mm})$ & $1.334 \times 10^{10}, 0.005,40.1,63.9,8$ \\
Rotating speeds of the rotor system & $\omega_{\mathrm{low}}, \omega_{\mathrm{high}}(\mathrm{rad} / \mathrm{s}), \gamma_{\omega}$ & $1500,2700,1.8$ \\
Parameters of the maneuvering flight & $\omega_{\mathrm{b} z}(\mathrm{rad} / \mathrm{s}), R_{\mathrm{b} z}(\mathrm{~m})$ & $\pi, 3$
\end{tabular}

characteristics of the dual-rotor system. The bending displacements $\left(x_{2}\right.$ and $\left.y_{2}\right)$ of the disk $m_{2}$ are selected to reveal the bending characteristics. In addition, the motion of the dual-rotor system consists of some responses with low frequency and large amplitude because of the time-varying influence of the maneuvering flight. They are useless for the analysis of the rub-impact fault features. Therefore, a highpass filter is applied to the response of the dual-rotor system. The detailed calculating process is shown in Figure 6.

\section{Discussion of Numerical Results}

3.1. Transient Responses without Rub-Impact Fault. The transient responses of the dual-rotor system are studied firstly without considering the rub -impact fault. The generalized resultant force of the maneuver load and gravity applied to the disk $m_{2}$ is chosen as the example for illustrating the effect of the barrel roll flight. As shown in Figure 7, the rotor system suffers gravity and additional inertial maneuver load during the barrel roll flight $(t \in[2 \mathrm{~s}, 4 \mathrm{~s}])$. Because the angle between the maneuver load and gravity varies, the generalized resultant force of the maneuver load and gravity is not constant but time-varying. The transient axis orbit of the disk $m_{2}$ corresponding to this process is given in Figure 8. It can be seen that at first $(t \in[0,2 \mathrm{~s})$ the rotor system keeps steady response with small amplitude. As the aircraft enters into the barrel roll flight $(t \in[2 \mathrm{~s}, 4 \mathrm{~s}])$, the axis orbit of the rotor system is deviated entirely. The offset of the axis orbit changes over time due to the varying additional generalized force. Therefore, the rub-impact fault of the rotor system can be induced by the barrel roll flight and the levels of the rub- 


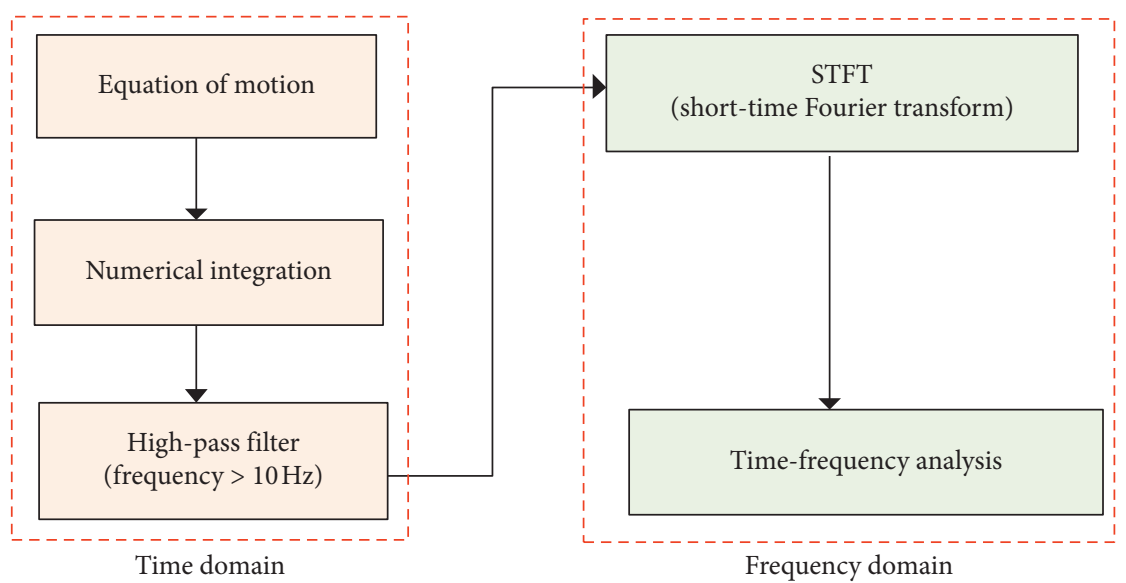

Figure 6: Calculating process.

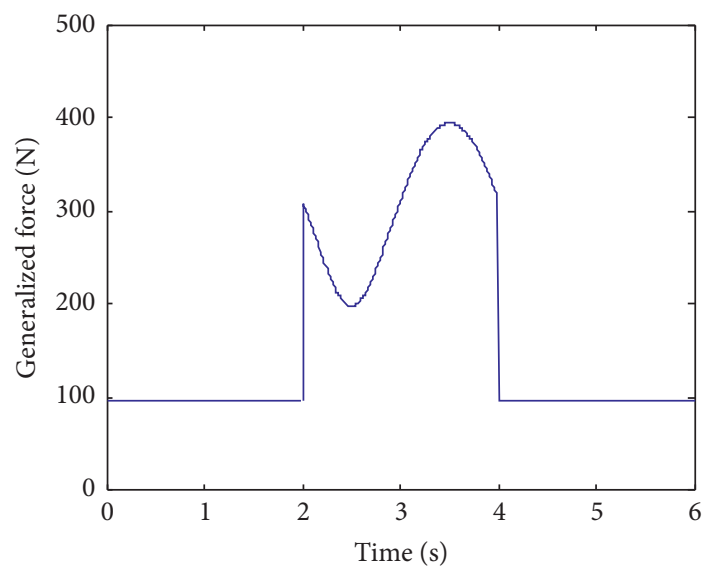

FIgURE 7: Generalized resultant force of the maneuver load and gravity applied to the disk $\mathrm{m}_{2}$.

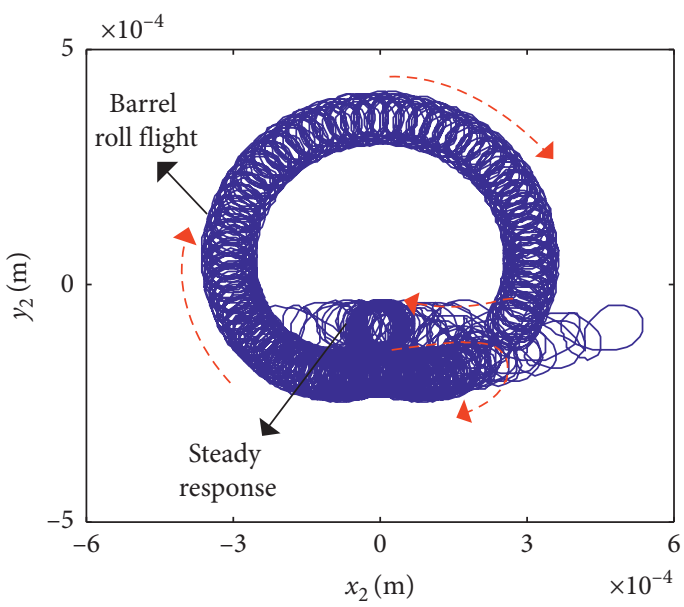

FIgURE 8: Transient axis orbit of the disk $\mathrm{m}_{2}$ during the flight of the aircraft.

impact are time-varying during the flight. After the barrel roll flight, the rotor system returns to the steady response again.

Without considering the rub-impact fault, the transient time-frequency waterfall curves of the bending and torsional motions of the rotor system are shown in Figure 9. Form
Figure 9(a), we know that the bending responses of the rotor system are mainly based on the rotating frequencies $\omega_{\text {low }}$ and $\omega_{\text {high }}$. In addition, at the start and end of the barrel roll flight $(t=2 \mathrm{~s}$ and $t=4 \mathrm{~s})$, the natural bending frequency of the rotor system $\omega_{\mathrm{b}}$ is aroused because of the sudden disturbance of the flight. As shown in Figure 9(b), the torsional responses of the rotor system display combined rotating frequency $\omega_{\text {high }}-\omega_{\text {low }}$ which is caused by the unbalanced force of the rotor system. Moreover, we know that the barrel roll flight has little effect on the time-frequency responses of the torsional motion of the rotor system.

\subsection{Transient Responses with Rub-Impact Fault}

3.2.1. Effect of Rub-Impact Stiffness. Taking the rub-impact stiffness as the control parameter, the transient time-frequency waterfall curves of the bending and torsional motions of the rotor system for $k_{\mathrm{r}}=2 \times 10^{6}, 8 \times 10^{6}$ and $1.4 \times 10^{7} \mathrm{~N} / \mathrm{m}$ are shown in Figures 10-12, respectively. The other parameters are listed in Table 1. A variety of comparisons for the rub-impact fault features of the bending and torsional motions are observed.

From Figure $10(\mathrm{a})$, we can see that for $k_{\mathrm{r}}=2 \times 10^{6} \mathrm{~N} / \mathrm{m}$, the bending motion of the rotor system shows no rubimpact feature. There are only the rotating frequencies $\omega_{\text {low }}$ and $\omega_{\text {high }}$ and the natural bending frequency $\omega_{\mathrm{b}}$ in the waterfall curves which are the same as the responses in Figure 9(a). However, the rub-impact fault does happen. As shown in Figure 10(b), the torsional motion of the rotor system displays apparent rub-impact behavior during the barrel roll flight. Because of the transmission of the bendingtorsional coupling motion, the torsional responses show the rotating fault frequencies $\omega_{\text {low }}$ and $\omega_{\text {high }}$ during the process of the rub-impact. It demonstrates that at the low rubimpact stiffness, the torsional responses work better than bending responses in rub-impact fault detection.

When the rub-impact stiffness increases from $k_{\mathrm{r}}=2 \times 10^{6} \mathrm{~N} / \mathrm{m}$ to $k_{\mathrm{r}}=8 \times 10^{6} \mathrm{~N} / \mathrm{m}$, by comparing Figure 11(a) with Figure 10(a), we can see that bending motion of the rotor system shows the fault frequencies. It consists of the fractional fault frequency $(1 / 2) \omega_{\text {low }}$ and the 


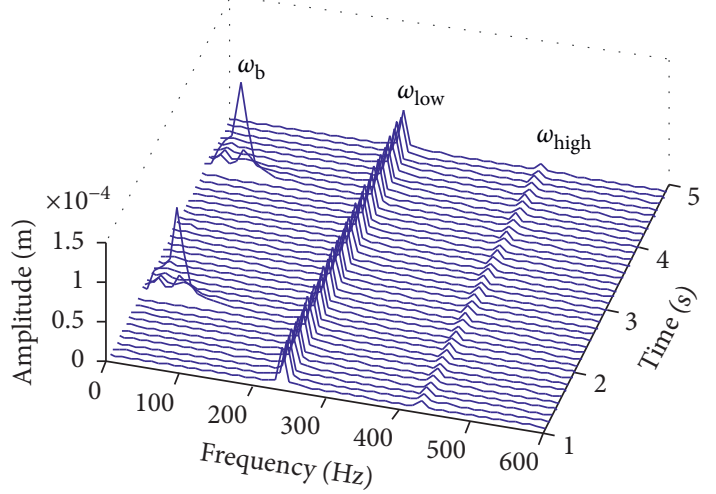

(a)

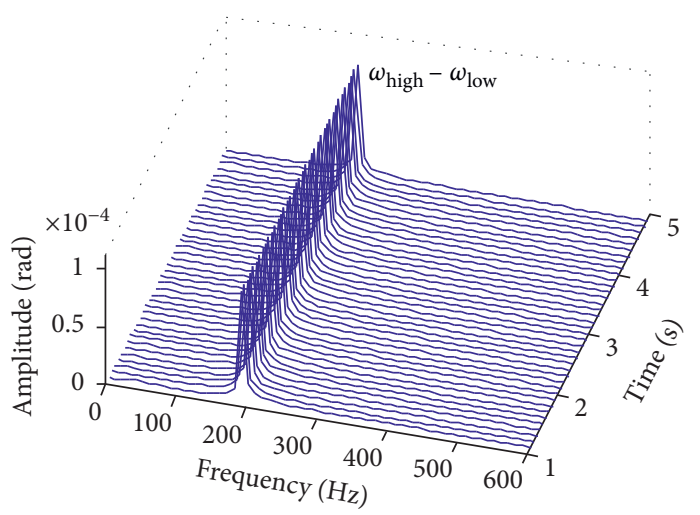

(b)

Figure 9: Transient time-frequency waterfall curves of the bending and torsional motions of the rotor system without the rub-impact fault. (a) Bending motion and (b) torsional motion.

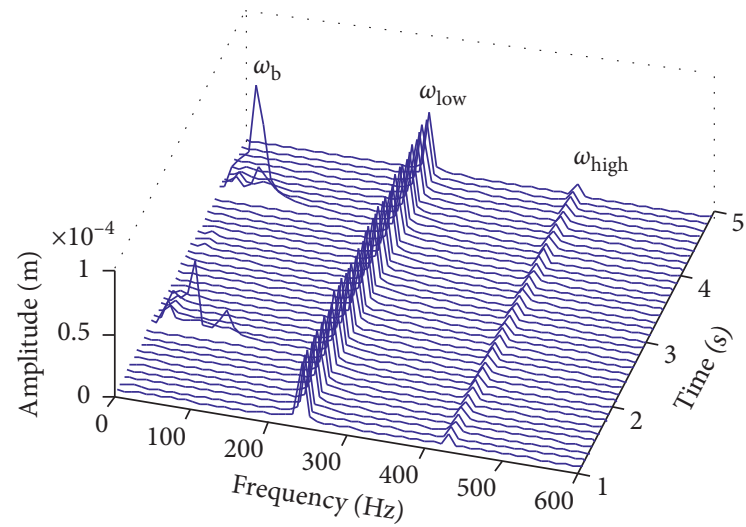

(a)

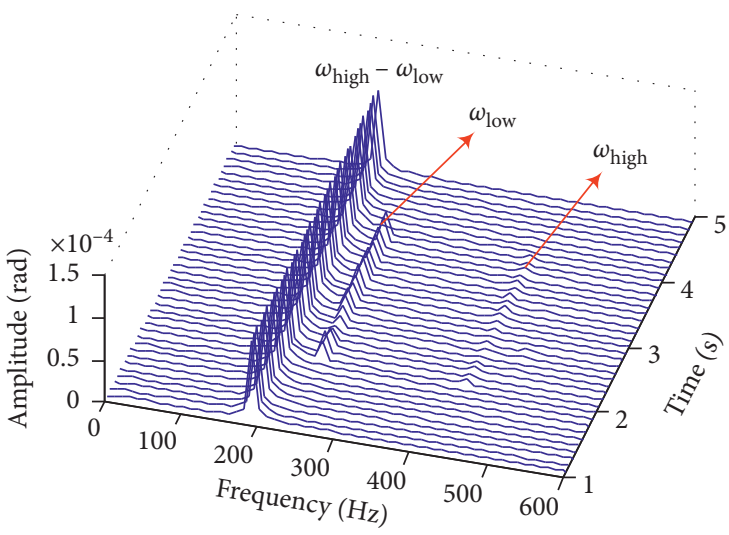

(b)

Figure 10: Transient time-frequency waterfall curves of the bending and torsional motions of the rotor system for $\mathrm{kr}=2 \times 106 \mathrm{~N} / \mathrm{m}$. (a) Bending motion and (b) torsional motion.

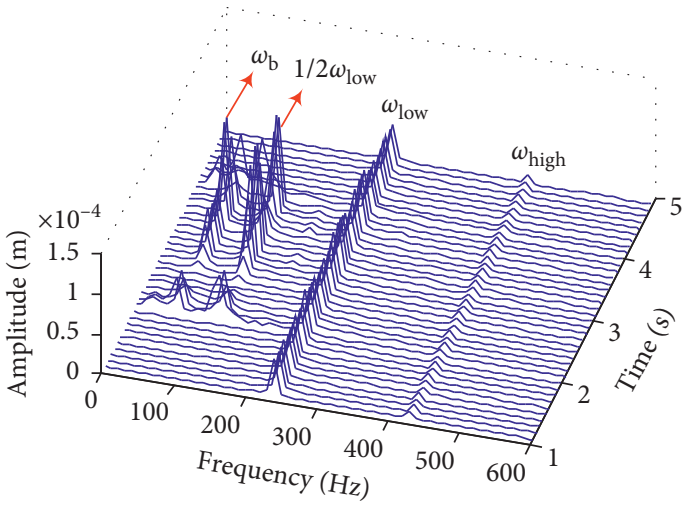

(a)

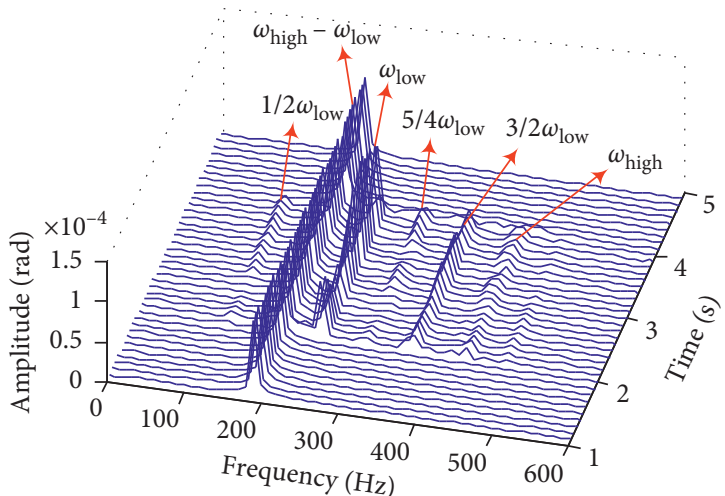

(b)

Figure 11: Transient time-frequency waterfall curves of the bending and torsional motions of the rotor system for $\mathrm{kr}=8 \times 106 \mathrm{~N} / \mathrm{m}$. (a) Bending motion and (b) torsional motion.

natural bending frequency $\omega_{\mathrm{b}}$ during the barrel roll flight. The amplitude of the fault frequencies is changed over time due to the variable generalized forces. As shown in
Figure 11(b), the torsional motion of the rotor system behaves more complicated fault frequencies. It contains the fractional fault frequencies $(1 / 2) \omega_{\text {low }}, \quad(5 / 4) \omega_{\text {low }}$, and 
$(3 / 2) \omega_{\text {low }}$ and the rotating fault frequencies $\omega_{\text {low }}$ and $\omega_{\text {high }}$. However, the natural bending frequency $\omega_{\mathrm{b}}$ does not transmit to the torsional motion. Therefore, at the middle segment of the rub-impact stiffness, the bending responses and torsional responses both can be used for the rub-impact detection.

When the rub-impact stiffness continues increasing to $k_{\mathrm{r}}=1.4 \times 10^{7} \mathrm{~N} / \mathrm{m}$, the transient time-frequency waterfall curves of the bending and torsional motions are shown in Figures 12(a) and 12(b), respectively. As shown in Figure 12(a), the bending responses of the rotor system show the fractional fault frequency $(1 / 2) \omega_{\text {low }}$. But, the free vibration component $\omega_{\mathrm{b}}$ does not arise because the rub-impact stiffness is strengthened. The torsional responses in Figure 12(b) still contain complicated fractional fault frequencies $(1 / 2) \omega_{\text {low }}$ and $(3 / 2) \omega_{\text {low }}$ and the rotating fault frequencies $\omega_{\text {low }}$ and $\omega_{\text {high }}$. Therefore, at the high rub-impact stiffness, the bending responses and torsional responses still can be used for the rub-impact detection.

The spectrum cascades of the bending and torsional motions with varied rub-impact stiffness are shown in Figure 13. For every certain rub-impact stiffness, we chose the transient responses of the rotor system during the maneuver flight $(t \in[2.2 \mathrm{~s}, 3.8 \mathrm{~s}])$ to obtain the spectrum. According to the rub-impact stiffness range, the spectrum cascades are divided into three bifurcation regions, in which $k_{r}=5.5 \times 10^{6} \mathrm{~N} / \mathrm{m}$ and $1.15 \times 10^{7} \mathrm{~N} / \mathrm{m}$ are the bifurcation points. When $k_{r}<5.5 \times 10^{6} \mathrm{~N} / \mathrm{m}$, the bending responses show no rub-impact features, but the torsional responses displays the early rotating fault frequencies. With $k_{r}>5.5 \times 10^{6} \mathrm{~N} / \mathrm{m}$, the bending responses begin to show the fractional fault frequency and natural bending frequency. In addition, the natural bending frequency of the bending motion disappears at $k_{r}>1.15 \times 10^{7} \mathrm{~N} / \mathrm{m}$ because of the further enhancement of the rub-impact stiffness. Comparing with the bending responses, the torsional responses contain more complicated fault frequencies within the whole region of the rub-impact stiffness. Moreover, the amplitude of the rotating fault frequency $\omega_{\text {low }}$ increases linearly with the enhancement of the rub-impact stiffness which can be used for qualitative detection of the rub-impact stiffness. Therefore, the characteristic frequencies of the torsional motion will be more advantageous for the state detection and rub-impact fault diagnosis.

3.2.2. Effect of Rub-Impact Friction Coefficient. Taking the rub-impact friction coefficient as the control parameter, the spectrum cascades of the bending and torsional motions of the rotor system for $\mu \in(0,0.3]$ are shown in Figure 14(a) and $14(\mathrm{~b})$, respectively. The transient rub-impact responses $(t \in[2.2 \mathrm{~s}, 3.8 \mathrm{~s}])$ are chosen to obtain the spectrum for the certain rub-impact friction coefficient.

As shown in Figure 14(a), the friction coefficient has little effect on the bending responses. The bending responses show the fractional fault frequency $(1 / 2) \omega_{\text {low }}$ and the natural bending frequency $\omega_{b}$ within the whole region of the friction coefficient. It proves that rub-impact fault characteristics of

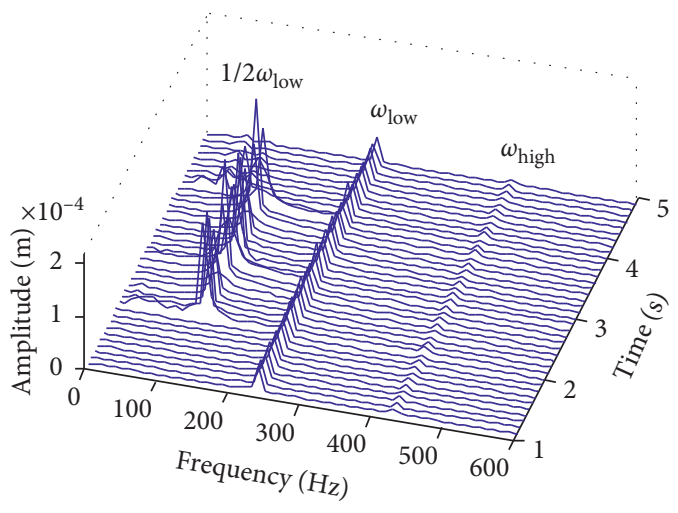

(a)

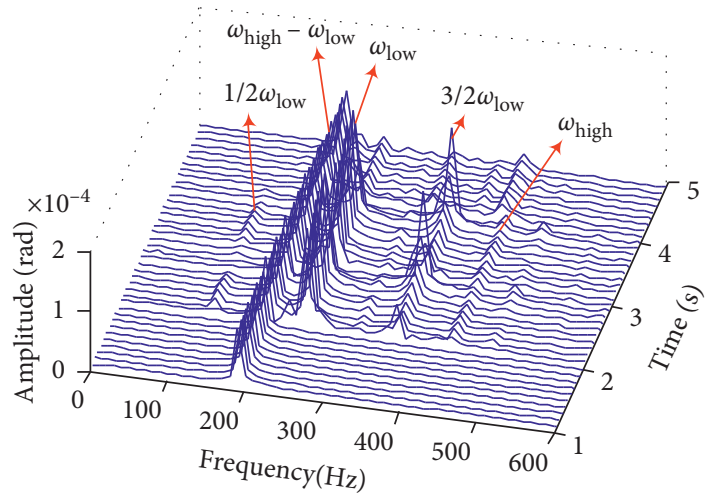

(b)

Figure 12: Transient time-frequency waterfall curves of the bending and torsional motions of the rotor system for $k_{r}=1.4 \times 107 \mathrm{~N} / \mathrm{m}$. (a) Bending motion and (b) torsional motion.

the bending motion are mainly caused by the rub-impact stiffness but not the friction coefficient. However, the rubimpact friction coefficient affects the torsional motion greatly. From Figure 14(b), we can see that the amplitude of the fault frequencies $(1 / 2) \omega_{\text {low }},(3 / 2) \omega_{\text {low }}, \omega_{\text {low }}$, and $\omega_{\text {high }}$ increases with the increase of the friction coefficient. In addition, the rotating fault frequency $\omega_{\text {low }}$ arises even at the little friction coefficient. It demonstrates that the torsional motion of the rotor system is sensitive to the rub-impact friction coefficient. The larger the friction coefficient is, the more obvious the fault characteristics of the torsional motion are. Therefore, the friction coefficient plays a decisive role on the transmission of the bending-torsional coupling motion.

3.2.3. Effect of Rotating Speed. To show the rub-impact fault characteristics of the bending and torsional motions with varied rotating speeds, the spectrum cascades for $\omega_{\text {low }} \in(500(\mathrm{rad} / \mathrm{s}), 3000(\mathrm{rad} / \mathrm{s})]$ are shown in Figure 15(a) and 15(b), respectively. The transient rub-impact responses $(t \in[2.2 \mathrm{~s}, 3.8 \mathrm{~s}])$ are chosen to obtain the spectrum for the certain rotating speed.

According to the frequency features of the bending responses, the rotating speeds are divided into three regions: low-speed region, intermediate-speed region, and high-speed 


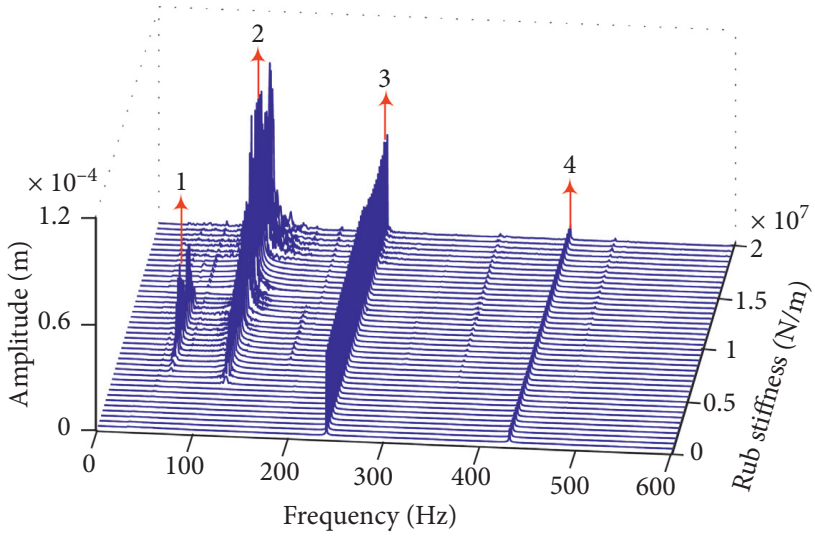

1. $\omega_{\mathrm{b}}$ $2.1 / 2 \omega_{\text {low }}$

$$
\begin{aligned}
& \text { 3. } \omega_{\text {low }} \\
& \text { 4. } \omega_{\text {high }}
\end{aligned}
$$

(a)

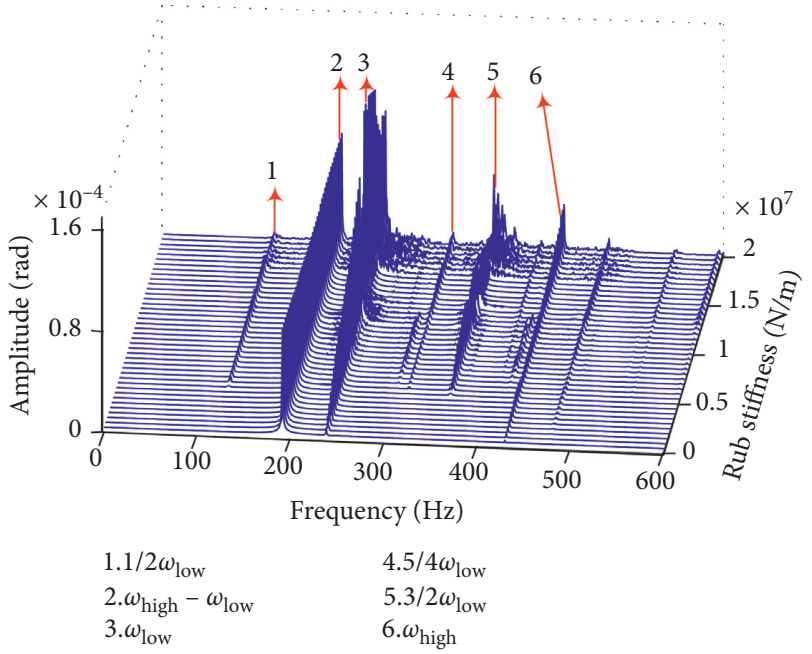

(b)

FIGURE 13: Spectrum cascades of the bending and torsional motions with varied rub-impact stiffness $\left(k_{\mathrm{r}} \in\left[5 \times 10^{5} \mathrm{~N} / \mathrm{m}, 2 \times 10^{7} \mathrm{~N} / \mathrm{m}\right]\right)$. (a) Bending motion and (b) torsional motion.

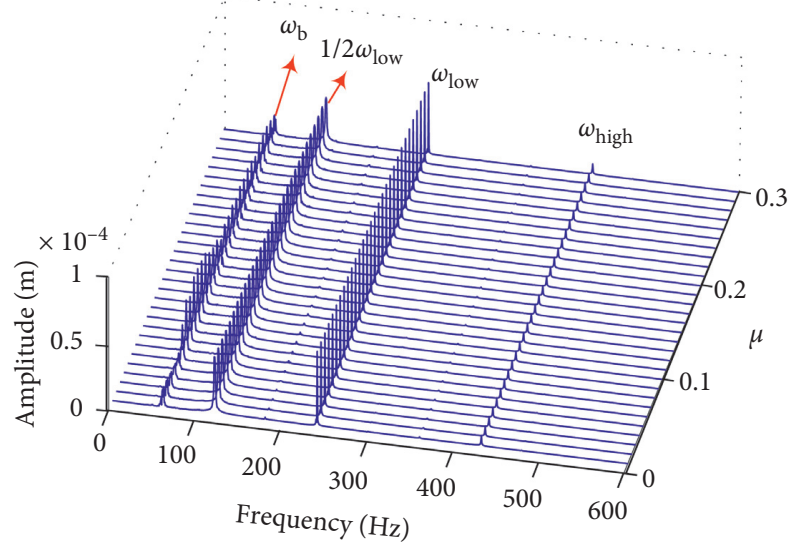

(a)

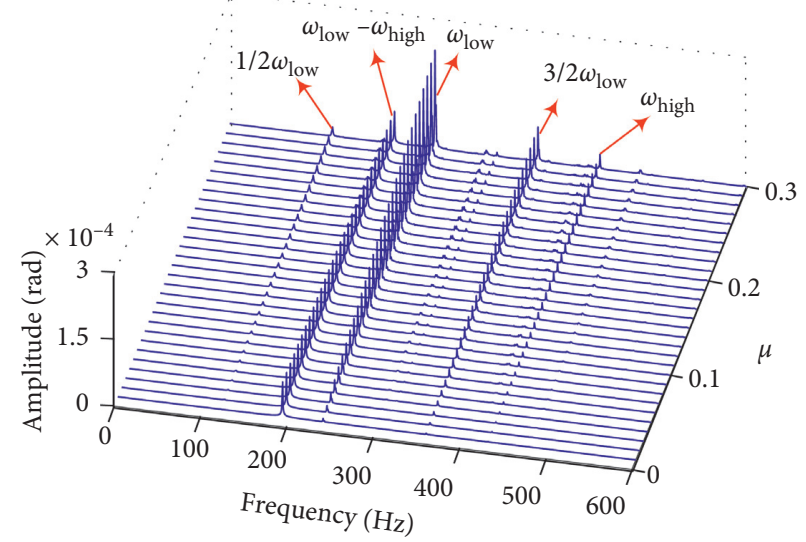

(b)

FIGURE 14: Spectrum cascades of the bending and torsional motions with varied rub-impact friction coefficients $(\mu \in(0,0.3])$. (a) Bending motion and (b) torsional motion.

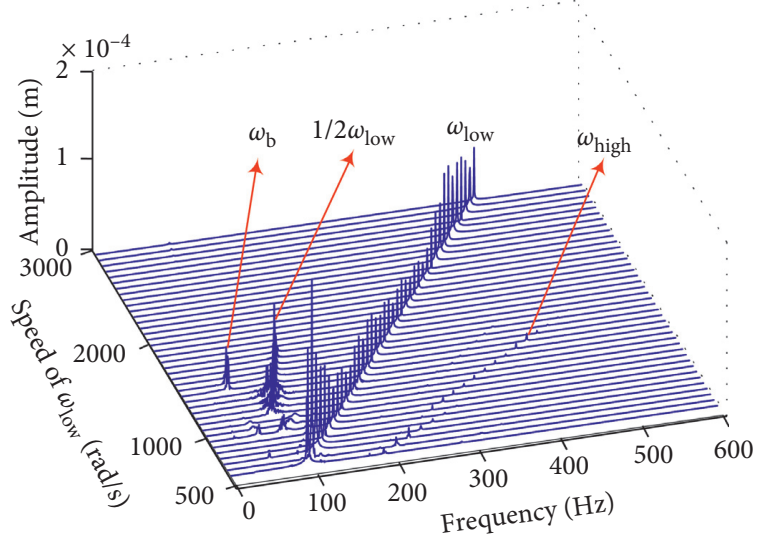

(a)

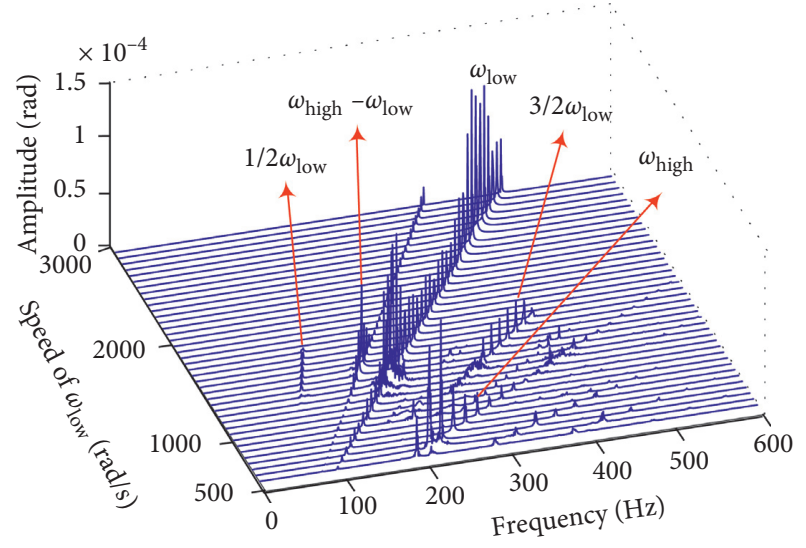

(b)

FIGURE 15: Spectrum cascades of the bending and torsional motions with varied rotating speeds $\left(\omega_{\text {low }} \in(500(\mathrm{rad} / \mathrm{s}), 3000(\mathrm{rad} / \mathrm{s})]\right)$. (a) Bending motion and (b) torsional motion. 
region. The bending responses display fractional rub-impact fault frequency $(1 / 2) \omega_{\text {low }}$ and natural bending frequency $\omega_{\mathrm{b}}$ within the intermediate speed region $\left(\omega_{\text {low }} \in[1140(\mathrm{rad} / \mathrm{s}), 1740(\mathrm{rad} / \mathrm{s})]\right)$. However, at the lowspeed region and high-speed region, the bending responses show no fault frequency. Comparing with the bending responses, the torsional responses display rub-impact fault characteristics within the whole region of the rotating speed. In addition, there are more complicated fractional fault frequencies at the intermediate speed region.

The transient time-frequency waterfall curves of the bending and torsional motions for $\omega_{\text {low }}=1500 \mathrm{rad} / \mathrm{s}$ and $1800 \mathrm{rad} / \mathrm{s}$ are chosen as the examples for illustrating the effect of the rotating speed.

The responses for $\omega_{\text {low }}=1500 \mathrm{rad} / \mathrm{s}$ have been obtained, and the results are shown in Figure 11. It can be seen that at the intermediate speed region, the bending and torsional responses both show the rub-impact fault frequencies. The bending responses display fractional fault frequency $(1 / 2) \omega_{\text {low }}$ and the natural bending frequency $\omega_{\mathrm{b}}$. The torsional responses behave more complicated fractional fault frequencies $(1 / 2) \omega_{\text {low }},(5 / 4) \omega_{\text {low }}$, and $(3 / 2) \omega_{\text {low }}$ and the rotating fault frequencies $\omega_{\text {low }}$ and $\omega_{\text {high }}$. Therefore, at the intermediate speed region, the bending and torsional responses both can be used for the rub-impact fault detection.

However, this conclusion is inapplicable within the lowspeed region and high-speed region. The bending and the torsional responses for $\omega_{\text {low }}=1800 \mathrm{rad} / \mathrm{s}$ are shown in Figures 16(a) and 16(b) for explanation. As shown in Figure 16(a), the bending responses show no fault frequency during the maneuvering flight. Hence, at $\omega_{\text {low }}=1800 \mathrm{rad} / \mathrm{s}$, the spectrum of the bending responses cannot be used to distinguish the occurrence of the rub-impact fault. From Figure 16(b), we can see that the apparent rotating fault frequency $\omega_{\text {low }}$ is transmitted to the torsional motion because of the influence of the rub-impact. Therefore, within the whole region of the rotating speed, the torsional responses will be more effective than the bending responses for the rub-impact fault detection.

\section{Discussion of Experimental Results}

4.1. Experimental Device. In this section, an experiment is carried out to verify the results obtained by the numerical simulation. Figure 17(a) shows the main experimental devices, which consist of a rotor test rig, a rub-impact device, a base motion platform, two rotary encoders, two displacement sensors, and a set of data acquisition system. Figure 17(b) displays the rub-impact device. The stator of the rub-impact device is a circular truncated cone, whose inner race is slightly larger than that of the disc. The material of the stator is steel. The rub-impact device can be moved from right to left, so the clearance of the stator and disc can be adjusted from 0 to $5 \mathrm{~mm}$. The rub-impact process can be well imitated because of the convenient clearance adjustment.

Figure 18 shows the schematic diagram of the main experimental device. The rub-impact rotor system installed on the base motion platform is used for imitating the aeroengine mounted on the aircraft. A single-rotor test rig is adopted to verify the simulation results qualitatively. There are two sets of control system: rotor motor control system and base motion platform control system. Then, with the rotor at the constant speed, the whole rotor system can also rotate around the rolling shaft of the base motion platform, so as to simulate the vibration of the aero-engine during the barrel roll flight. The rolling radius and maximum rolling speed of the base motion platform are $0.4 \mathrm{~m}$ and $\pi \mathrm{rad} / \mathrm{s}$, respectively. In addition, to carry out the signal acquisition and the electric power supply of the motor, a slip ring is added to the base motion platform system, through which the above function can be achieved on the premise of the barrel roll flight of the base motion platform.

As for the data acquisition system, two eddy current displacement sensors are used to measure the bending displacements of the rotating shaft in the horizontal and vertical directions. The sampling frequency of the displacement data is set to $2,000 \mathrm{~Hz}$. The rotary encoder can pick up the real-time rotating speed of the shaft. Therefore, one rotary encoder is installed at the left shaft end of the rotor and the other one is mounted at the right shaft end. The torsional responses of the rotor system are expressed by the relative rotation speed difference of the two shaft ends $\left(\Delta \omega=\omega_{1}-\omega_{5}\right)$. The sampling frequency of the rotating speeds of the two shaft ends is set to $12,800 \mathrm{~Hz}$. Because of the slowly time-varying influence of the maneuvering flight, a high-pass filter (frequency $>2 \mathrm{~Hz}$ ) is applied to the vibration data of the rotor test rig before the time-frequency processing.

4.2. Experimental Results Analysis. The rotating speed of the rotor test rig is set to $\omega=1200 \mathrm{rpm}$, and the rolling speed of the base motion platform is chosen as $\omega_{\mathrm{b}}=\pi \mathrm{rad} / \mathrm{s}$. The experimental process of the transient barrel roll flight of the base motion platform is the same as the simulation process: at first $(t \in[0 \mathrm{~s}, 2 \mathrm{~s}))$, the base motion platform keeps the steady-state flight, and it enters into the barrel roll flight at $t=2 \mathrm{~s}$ and quits the barrel roll flight at $t=4 \mathrm{~s}$. Then, it returns to the steady flight again $(t \in(4 \mathrm{~s}, 6 \mathrm{~s}])$.

In the first place, the model of the barrel roll flight is verified. As shown in Figure 19, the rotor test rig behaves steady responses with small amplitude firstly $(t \in[0 \mathrm{~s}, 2 \mathrm{~s}))$. Then, with the base motion platform entering into the barrel roll flight $(t \in[2 \mathrm{~s}, 4 \mathrm{~s}])$, the axis orbit of the rotor test rig is deviated entirely. After the barrel roll flight $(t \in((4 \mathrm{~s}, 6 \mathrm{~s}])$, the vibration of the rotor test rig returns to steady responses again. The axis orbits of the rotor test rig influenced by the maneuvering flight are basically the same as the simulation results shown in Figure 8, which demonstrates the validity of the mathematical model of the barrel roll flight.

In the second place, the bending and torsional responses of the rotor test rig are investigated to validate the simulation results. The transient time histories of the bending and torsional motions are shown in Figures 20(a) and 20(b), respectively. From Figure 20(b), we can see that the amplitude of the torsional responses increase evidently during 


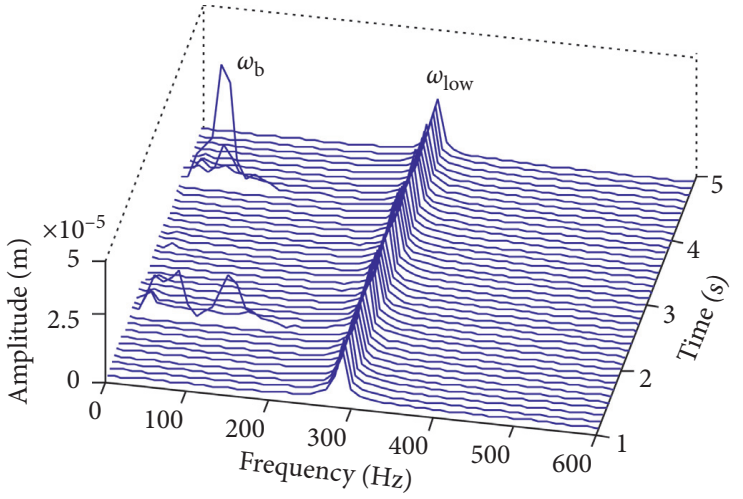

(a)

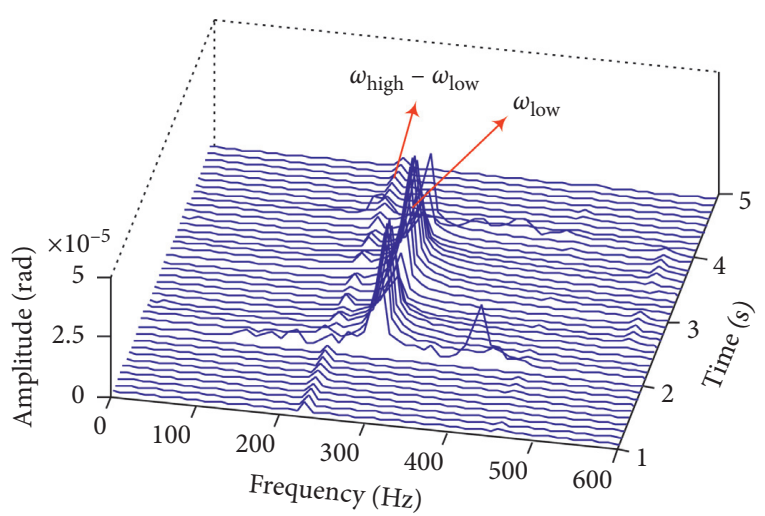

(b)

FIgURE 16: Transient time-frequency waterfall curves of the bending and torsional motions of the rotor system for $\omega_{\text {low }}=1800 \mathrm{rad} / \mathrm{s}$. (a) Bending motion and (b) torsional motion.

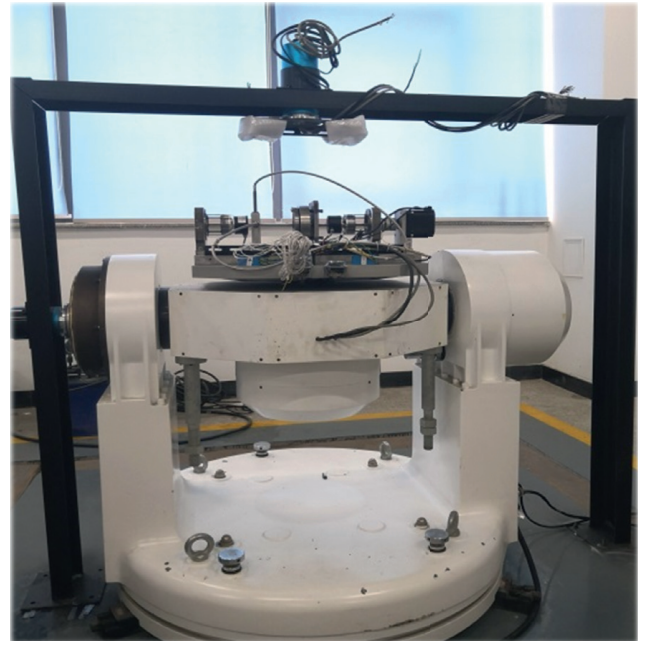

(a)

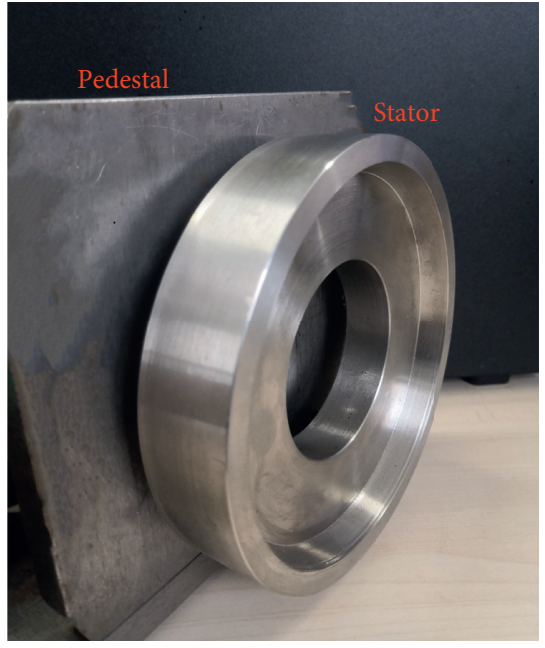

(b)

FIgURE 17: Main experimental devices and rub-impact device. (a) Main experimental devices and (b) rub-impact device.

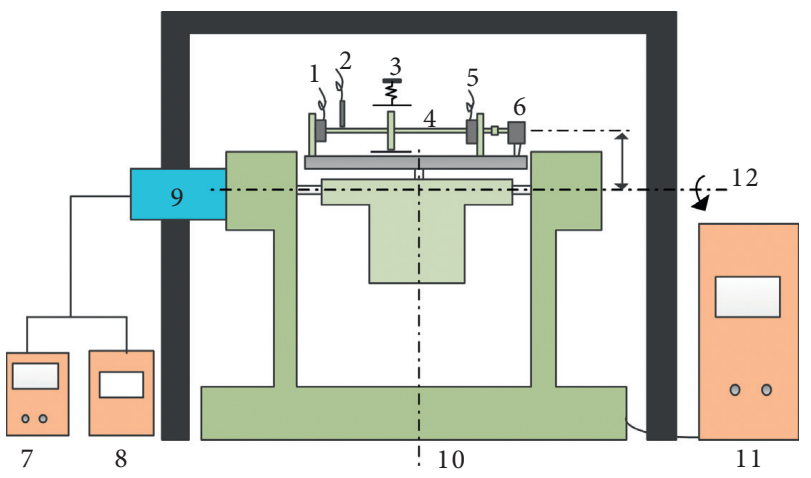

FIGURE 18: Schematic diagram of the experimental device. 1, rotary encoder, 2, displacement sensors, 3, rub-impact device, 4, rotor system, 5 , rotary encoder, 6 , motor, 7 , rotor control system, 8 , data acquisition system, 9, slip ring, 10, base motion platform, 11, base motion platform control system, 12, rolling shaft. the barrel roll flight which indicates the occurrence of the rub-impact fault.

To further reveal the rub-impact fault characteristics of the bending and torsional responses, the transient timefrequency waterfall curves of them are shown in Figures 21(a) and 21(b), respectively. As shown in Figure 21(a), the bending responses of the rotor test rig show no apparent fault frequency. Thus, the bending responses cannot be used for rub-impact fault detection at this rotating speed. However, the torsional responses of the rotor test rig in Figure 21(b) display rotating fault frequency $\omega$ during the barrel roll flight, which indicates the occurrence of the rubimpact fault. According to the simulation analysis in Figure 15, the frequency spectrums of the bending responses do not show apparent rub-impact fault characteristics at the low rotating speed region, but the distinguishable rotating fault frequency $\omega_{\text {low }}$ would be transmitted to the torsional motion 


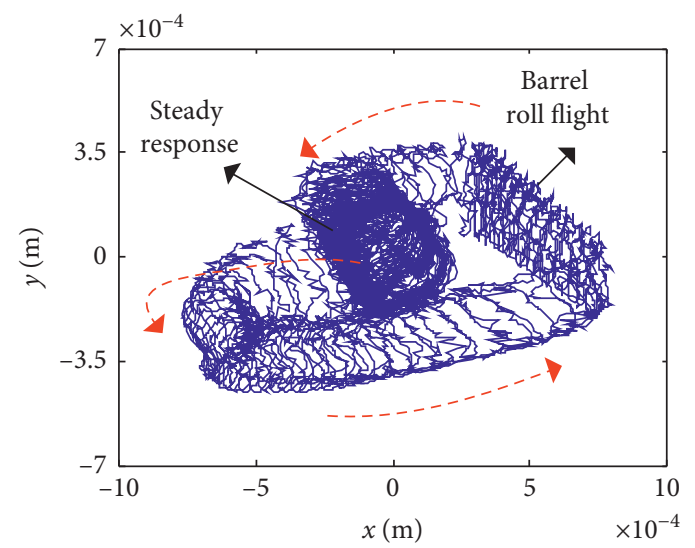

Figure 19: Transient axis orbit of the rotor test rig during the flight of the base motion platform $(t \in[0 \mathrm{~s}, 6 \mathrm{~s}])$.

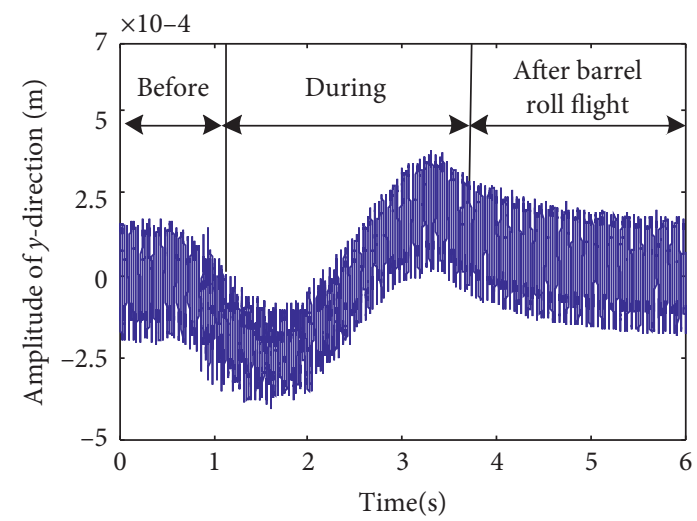

(a)

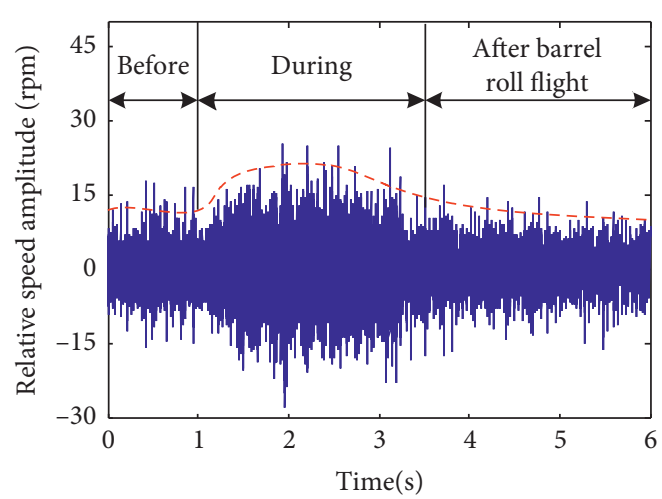

(b)

Figure 20: Transient time history of the bending and torsional motions of the rotor test fig during the flight of the base motion platform $(t \in[0 \mathrm{~s}, 6 \mathrm{~s}])$. (a) Bending motion and (b) torsional motion.

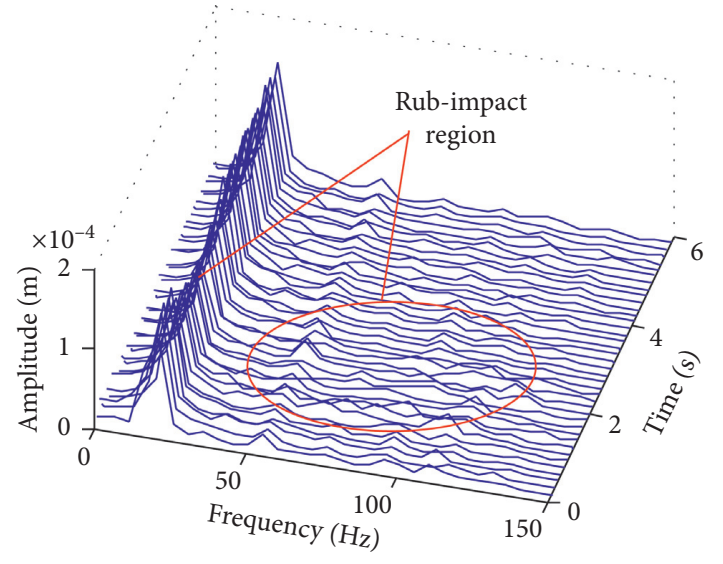

(a)

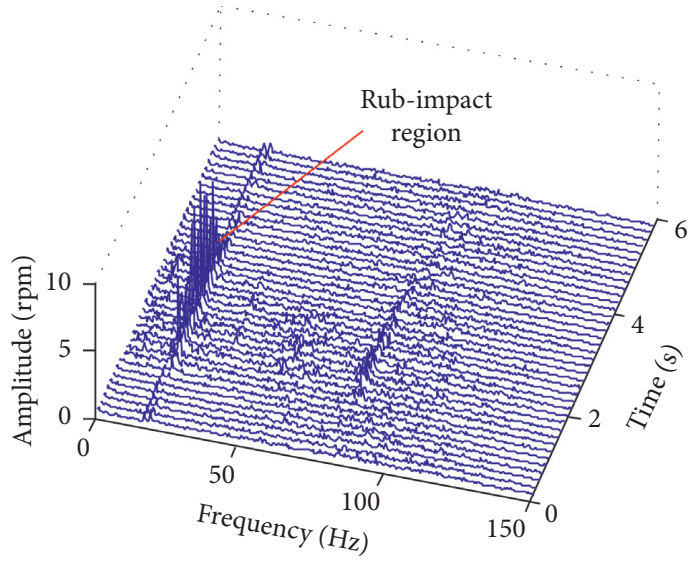

(b)

FIgURE 21: Transient time-frequency waterfall curves of the bending and torsional motions of the rotor test rig during the flight of the base motion platform $(t \in[0 \mathrm{~s}, 6 \mathrm{~s}])$. (a) Bending motion and (b) torsional motion. 


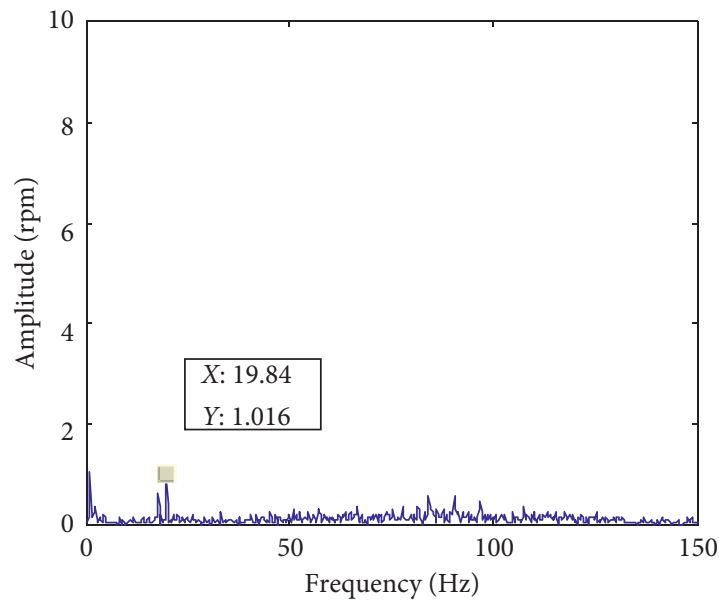

(a)

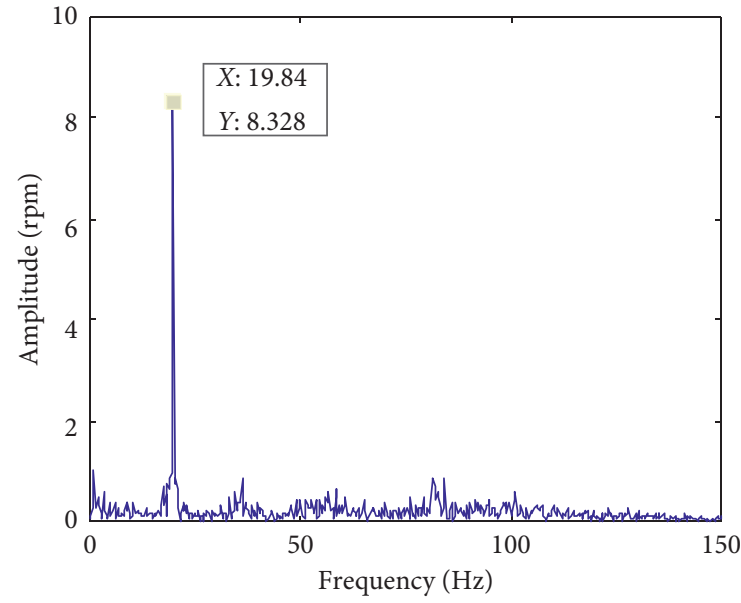

(b)

Figure 22: Spectrums of the transient torsional motions at $t \in[1 \mathrm{~s}, 1.2 \mathrm{~s}]$ (steady flight) and at $t \in[2.5 \mathrm{~s}, 2.7 \mathrm{~s}]$ (maneuvering flight). (a) $t \in[1 \mathrm{~s}, 1.2 \mathrm{~s}]$ and (b) $t \in[2.5 \mathrm{~s}, 2.7 \mathrm{~s}]$.

because of the influence of the rub-impact. Thus, the bending and torsional vibration phenomena of the rotor test rig are coincident with the frequency characteristics of the simulation results, which demonstrates the dynamics model established in the study is effective and suitable.

The transient torsional responses, at $t \in[1 \mathrm{~s}, 1.2 \mathrm{~s}]$ (steady flight) and at $t \in[2.5 \mathrm{~s}, 2.7 \mathrm{~s}]$ (maneuver flight), are separately chosen for the spectrums. As shown in Figure 22, as the rotor system transforms from nonrubbing to rubimpact, the amplitude of the rotating fault frequency $\omega$ increases from $1.016 \mathrm{rpm}$ to $8.328 \mathrm{rpm}$ in which the increment reaches $719.7 \%$. Therefore, the torsional responses can be better used for rub-impact fault diagnose at the low speed region. The experimental results verify the validity of the simulation results qualitatively.

\section{Conclusions}

In this study, the transient time-frequency characteristics of the bending and torsional responses of a rub-impact dual-rotor system are investigated considering the barrel roll flight of an aircraft. The equations of the bending-torsional coupling motion are established with the consideration of a low-pressure rotor rub-impact fault. The Runge-Kutta method is adopted to detect the bending and torsional responses, which are influenced by the rub-impact stiffness, friction coefficient, and rotating speed. Some conclusions are as follows:

(1) The unbalanced force and the friction torque caused by the rub-impact fault are the factors leading to the bending-torsional coupling motion of the rotor system. Under the influences of the coupled factors, the torsion responses display the fault frequencies similar to the bending responses, including fractional fault frequencies and rotating fault frequencies.

(2) The rub-impact stiffness affects bending vibration significantly and the torsional motion is sensitive to the friction coefficient. Therefore, the torsional responses show fault frequencies within the whole region of the rub-impact stiffness. The bending responses can only display fault characteristic frequencies at certain rub-impact stiffness.

(3) For the rotating speed, the bending vibration of the rub-impact rotor system will go through the bifurcation behavior $[5,25]$, in which the bending vibrations show no apparent fault frequency at low-speed region and high-speed region. However, the torsional motion displays fault frequencies within the whole region of the rotating speed.

(4) An experiment is carried out, verifying that the torsional responses work better for the rub-impact fault detection at the low speed region.

\section{Data Availability}

The experimental data used to support the findings of this study are available from the corresponding author upon request.

\section{Conflicts of Interest}

The authors declare that they have no conflicts of interest regarding this work.

\section{Acknowledgments}

This work was supported by the National Science and Technology Major Project (no. 2017-IV-0008-0045) and the National Natural Science Foundation of China (nos. 11672201 and 11872045).

\section{References}

[1] Y. S. Chen and H. B. Zhang, "Review and prospect on the research of dynamics of complete aero-engine systems," Acta Aeronautica et Astronautica Sinica, vol. 32, no. 8, pp. 13711391, 2011. 
[2] H.-B. Zhang, Y.-S. Chen, and J. Li, "Bifurcation on synchronous full annular rub of rigid-rotor elastic-support system," Applied Mathematics and Mechanics, vol. 33, no. 7, pp. 865-880, 2012.

[3] H. Ma, C. Shi, Q. Han, and B. Wen, "Fixed-point rubbing fault characteristic analysis of a rotor system based on contact theory," Mechanical Systems and Signal Processing, vol. 38, no. 1, pp. 137-153, 2013.

[4] L. Hou, H. Chen, Y. Chen, K. Lu, and Z. Liu, "Bifurcation and stability analysis of a nonlinear rotor system subjected to constant excitation and rub-impact," Mechanical Systems and Signal Processing, vol. 125, pp. 65-78, 2019.

[5] Z. Sun, J. Xu, and T. Zhou, "Analysis on complicated characteristics of a high-speed rotor system with rub-impact," Mechanism and Machine Theory, vol. 37, no. 7, pp. 659-672, 2002.

[6] A. Muszynska and P. Goldman, "Chaotic responses of unbalanced rotor/bearing/stator systems with looseness or rubs," Chaos, Solitons \& Fractals, vol. 5, no. 9, pp. 1683-1704, 1995.

[7] F. Chu and W. Lu, "Experimental observation of nonlinear vibrations in a rub-impact rotor system," Journal of Sound and Vibration, vol. 283, no. 3-5, pp. 621-643, 2005.

[8] H. Ma, T. Yu, Q. Han, Y. Zhang, B. Wen, and C. Xuelian, "Time-frequency features of two types of coupled rub-impact faults in rotor systems," Journal of Sound and Vibration, vol. 321, no. 3-5, pp. 1109-1128, 2009.

[9] Y. Yang, D. Cao, D. Wang, and G. Jiang, "Fixed-point rubbing characteristic analysis of a dual-rotor system based on the Lankarani-Nikravesh model," Mechanism and Machine Theory, vol. 103, pp. 202-221, 2016.

[10] Y. S. Chen and J. Li, "Research on bending-torsion coupling vibration of shaft system of turbine generator," Turbine Technology, vol. 54, no. 3, pp. 161-164, 2012.

[11] C. B. He, Y. J. Gu, and Z. Q. Chen, "Coupled flexural-torsion vibration of rotors with unbalance mass," Proceedings of the CSEE, vol. 26, no. 14, pp. 134-139, 2006.

[12] J. Li and Y.-S. Chen, "Combined resonance of low pressure cylinder-generator rotor system with bending-torsion coupling," Applied Mathematics and Mechanics, vol. 32, no. 8, pp. 957-972, 2011.

[13] K. M. A. Hussain and I. Redmond, "Dynamic response of two rotors connected by rigid mechanical coupling with parallel misalignment," Journal of Sound and Vibration, vol. 249, pp. 483-498, 2002.

[14] K. M. A. Hussain, "Dynamic stability of two rig rotors connected by a flexible coupling with angular misalignment," Journal of Sound and Vibration, vol. 266, pp. 217-234, 2003.

[15] A. K. Darpe, K. Gupta, and A. Chawla, "Coupled bending, longitudinal and torsional vibrations of a cracked rotor," Journal of Sound and Vibration, vol. 269, no. 1-2, pp. 33-60, 2004.

[16] A. K. Darpe, A. Chawla, and K. Gupta, "Analysis of the response of a cracked Jeffcott rotor to axial excitation," Journal of Sound and Vibration, vol. 249, no. 3, pp. 429-445, 2002.

[17] T. H. Patel and A. K. Darpe, "Coupled bending-torsional vibration analysis of rotor with rub and crack," Journal of Sound and Vibration, vol. 326, no. 3-5, pp. 740-752, 2009.

[18] Y. Lin and F. Chu, "The dynamic behavior of a rotor system with a slant crack on the shaft," Mechanical Systems and Signal Processing, vol. 24, no. 2, pp. 522-545, 2010.

[19] N. Wang and D. Jiang, "Vibration response characteristics of a dual-rotor with unbalance-misalignment coupling faults: theoretical analysis and experimental study," Mechanism and Machine Theory, vol. 125, pp. 207-219, 2018.

[20] W. Lu and F. Chu, "Radial and torsional vibration characteristics of a rub rotor," Nonlinear Dynamics, vol. 76, no. 1, pp. 529-549, 2014.

[21] Y. Yang, H. Ouyang, X. Wu, Y. Jin, Y. Yang, and D. Cao, "Bending-torsional coupled vibration of a rotor-bearingsystem due to blade-casing rub in presence of non-uniform initial gap," Mechanism and Machine Theory, vol. 140, pp. 170-193, 2019.

[22] K. Zhang and Q. Ding, "Lateral and torsional vibrations of a two-disk rotor-stator system with axial contact/rubs," International Journal of Applied Mechanics, vol. 01, no. 02, pp. 305-326, 2009.

[23] Q. Ding, "Lateral vibration of a rotor/bearing system with axial rub," Journal of Mechanical Strength, vol. 26, no. 2, pp. 132-137, 2004.

[24] H. Z. Xu, N. F. Wang, D. X. Jiang, T. Han, and D. W. Li, "Dynamic characteristics and experimental research of dualrotor system with rub-impact fault," Shock and Vibration, vol. 2016, Article ID 6239281, 2016.

[25] T. C. Zhang, S. Q. Cao, L. Q. Li, and H. L. Guo, "Analysis and experiment of coupled bending and torsional vibration of a rub-impact dual-rotor system," Journal of Aerospace Power, vol. 34, no. 3, pp. 643-655, 2019.

[26] L. Hou, Y. Chen, and Q. Cao, "Nonlinear vibration phenomenon of an aircraft rub-impact rotor system due to hovering flight," Communications in Nonlinear Science and Numerical Simulation, vol. 19, no. 1, pp. 286-297, 2014.

[27] Y. Yang, X. Ren, W. Qin, Y. Wu, and X. Zhi, "Analysis on the nonlinear response of cracked rotor in hover flight," Nonlinear Dynamics, vol. 61, no. 1-2, pp. 183-192, 2009.

[28] T. Gao, S. Q. Cao, L. L. Hou, and Y. H. Hou, "An experimental study on the nonlinear vibration phenomenon of a rotor system subjected to barrel roll flight and coupled rub-impact faults," Measurement, vol. 153, Article ID 107406, 2020.

[29] M. Dakel, S. Baguet, and R. Dufour, "Steady-state dynamic behavior of an on-board rotor under combined base motions," Journal of Vibration and Control, vol. 20, no. 15, pp. 2254-2287, 2014.

[30] H.-L. Zhou, G.-H. Luo, G. Chen, and F. Wang, "Analysis of the nonlinear dynamic response of a rotor supported on ball bearings with floating-ring squeeze film dampers," Mechanism and Machine Theory, vol. 59, pp. 65-77, 2013.

[31] F. Chu and Z. Zhang, "Bifurcation and chaos in a rub-impact Jeffcott rotor system," Journal of Sound and Vibration, vol. 210, no. 1, pp. 1-18, 1998. 